BNL-104352-2013-IR

\title{
Set-controlling Additive for Thermal Shock-resistant Cement
}

\author{
Prepared for \\ The U.S. Department of Energy \\ Energy Efficiency and Renewable Energy \\ Geothermal Technologies Program \\ 1000 Independence Avenue SW \\ Washington, D.C. 20585 \\ Prepared by \\ Toshifumi Sugama and Tatiana Pyatina \\ Sustainable Energy Technologies Department \\ Brookhaven National Laboratory \\ Upton, NY 11973-5000
}

November 2013

\section{Brookhaven National Laboratory}

\author{
U.S. Department of Energy \\ USDOE - Office of Energy Efficiency \& Renewable Energy
}

Notice: This manuscript has been authored by employees of Brookhaven Science Associates, LLC under Contract No. DE-AC02-98CH10886 with the U.S. Department of Energy. The publisher by accepting the manuscript for publication acknowledges that the United States Government retains a nonexclusive, paid-up, irrevocable, world-wide license to publish or reproduce the published form of this manuscript, or allow others to do so, for the United States Government purposes. 


\section{DISCLAIMER}

This report was prepared as an account of work sponsored by an agency of the United States Government. Neither the United States Government nor any agency thereof, nor any of their employees, nor any of their contractors, subcontractors, or their employees, makes any warranty, express or implied, or assumes any legal liability or responsibility for the accuracy, completeness, or any third party's use or the results of such use of any information, apparatus, product, or process disclosed, or represents that its use would not infringe privately owned rights. Reference herein to any specific commercial product, process, or service by trade name, trademark, manufacturer, or otherwise, does not necessarily constitute or imply its endorsement, recommendation, or favoring by the United States Government or any agency thereof or its contractors or subcontractors. The views and opinions of authors expressed herein do not necessarily state or reflect those of the United States Government or any agency thereof. 


\begin{abstract}
The present work discusses retardation of hydration of sodium metasilicate (SMS)-activated calcium aluminate cement (CAC)/Class F fly ash blend at $85^{\circ} \mathrm{C}$. Screening of common retarders, including citric-, tartaric-, and boric-acids, via isothermal calorimetric measurements identified tartaric acid as being the most efficient in delaying the set of the blend. None of these retarders compromised the development of long-term compressive strength or toughness at concentrations of up to $1 \%$ by weight of blend (bwob) at $200-$ and $300^{\circ} \mathrm{C}$. The reaction products of tartaric acid and the blend (or its components) were characterized by XRD, Fourier-transform infrared, Thermogravimetric Analysis (TGA), Inductively Coupled Plasma-Optical Emission Spectroscopy (ICP-OES) and micro Energy Dispersive X-ray spectroscopy in cements with high retarder concentrations (50/50 wt.\% blend component/TA) or low ones (1\% bwob TA) after short hydration times of 2 hours and long ones of 72 hours. The main conclusions drawn from this study were that SMS not only activates the hydration of water-inert fly ash F, but also delays the set of the CAC/fly ash F blend. Adding tartaric acid further retards the set of the blend and formation of crystalline hydrates at $85^{\circ} \mathrm{C}$, so promoting hydroxysodalite crystallization at $300^{\circ} \mathrm{C}$. Hypothesis to explain the set-retarding mechanism are proposed.
\end{abstract}




\section{Introduction}

Geothermal wells arguably present the most severe conditions that cement may experience. In addition to the chemically aggressive environment the cement is exposed to a significant thermal shock when wells constructed under relatively mild temperatures of about $80-100^{\circ} \mathrm{C}$ are moved into production and the temperature may go up by several hundred degrees. The differences in temperature between the injection- and production-heat-carrier fluids may further impose a constant thermal-shock on the cement in a highly fractured geothermal environment during the cement's lifetime.

To deal with this issue, our previous work [1] centered on formulating a thermal-shock-resistant cement (TSRC) consisting of two cement-forming reactants, calcium aluminate cement (CAC) and Class F fly ash, and one alkaline activator (sodium metasilicate). These three components as starting materials were mixed together to prepare the dry-blend cement system. When the cement slurry made by adding an appropriate amount of water to this dry system was autoclaved at $200^{\circ} \mathrm{C}$, it formed four crystalline hydration products, boehmite, katoite, hydrogrossular, and hydroxysodalite that were responsible for strengthening the cement. After testing this autoclaved cement by 5 -cycle $500^{\circ} \mathrm{C}$ heating-water quenching, we observed that three crystalline phasetransformations occurred: Boehmite $\rightarrow \gamma-\mathrm{Al}_{2} \mathrm{O}_{3}$, katoite $\rightarrow$ calcite, and hydroxysodalite $\rightarrow$ carbonated sodalite. Among those, the hydroxysodalite $\rightarrow$ carbonated sodalite transformation played a pivotal role in densifying the cementitious structure, and in sustaining the material's original compressive strength developed after autoclaving; additionally, it improved the resistance of the CAC to thermal shock.

As part of the ongoing R\&D, our work focuses on the placement technology for TSRC. With few exceptions, geothermal wells are not cemented at high temperatures. The fluids circulated during drilling cool the formation. The maximum circulating temperatures during cementing seldom exceed $116^{\circ} \mathrm{C}$ [2] with the average being around $85^{\circ} \mathrm{C}$. The downhole pressures rarely are above the water gradient in geothermal fields. For example, a maximum of 5,000 psi and a midpoint of 2,500 psi are typical for a US geothermal cementing (Mark Sauter, ThermaSource, personal communication). Although the formulation of Ordinary Portland cement systems with adequate thickening times usually is not a problem for such conditions, there is no up-to-date knowledge of the high temperature behavior of TSRC under conditions of shear and pressure. Normally, pumping times of up to 6 hours are required to place cements successfully. The requirement for the rapid development of mechanical properties after placing the cement imposes additional limitations on the acceptability of retarder systems. Even for CAC alone there is only a limited literature on its high-temperature pumpability, since applications of this cement in hot subterranean wells are limited [3].

From the very early studies of calcium-aluminate cements, various organic compounds were shown to retard the hydration of their major component, monocalcium aluminate [4]. Rodger and Double examined in some detail the retarding effect of citric acid on CAC hydration [5]. They concluded that citrate ions are not directly absorbed on the surface of the cement clinker, nor do they inhibit nucleation. Rather, it was proposed that there first was preferential complexation of calcium by citrate, alumina-gel precipitation, with later precipitation of citrate with calcium aluminate hydrates. Another study reported a significant delay in the hydration of calcium aluminates in the presence of tartaric acid [6]. Among the various retarders, tartaric-, citric-, and 
boric-acids are used both for Ordinary Portland Cement (OPC) and conventional calcium aluminate cement (CAC) [7-10]. We evaluated effect of these organic retarders on the hydration of CAC.

Sodium silicate delays the setting of CAC and both high- and low-Ca fly ashes, as is well documented [11-14]. Since the TSRC system contains sodium metasilicate as alkali activator of Class F fly ash, we studied the silicates' effects on the hydration of CAC and FAF separately at $85 \mathrm{C}$, and when combined in TSRC.

We divided our study into six major objectives : 1) Screening retarders most suitable for a TSRC slurry; 2) evaluating effect of the retarders on the compressive strength developed at hydrothermal temperatures of $85^{\circ}, 200^{\circ}$, and $300^{\circ} \mathrm{C} ; 3$ ) assessing the combined effect of the selected retarder and SMS on the initial cement hydration at high concentrations of the retarder; 4) analyzing the exothermal energy evolved during hydration of the retarded slurries; 5) detailing the solution- and solid phase-changes at early hydration times with low retarder concentrations; and, 6) recording the alteration in the composition of the crystalline phase of retarded cement at $85^{\circ}, 200^{\circ}$, and $300^{\circ} \mathrm{C}$. By integrating our findings we propose a model of the set-retarding mechanism.

\section{Experimental procedures}

\subsection{Materials}

Class F fly ash was obtained from Boral Material Technologies, Inc.; its chemical composition detected by micro energy-dispersive X-ray spectrometer ( $\mu \mathrm{EDX})$ was as follows; $49.3 \% \mathrm{SiO}_{2}$, $36.1 \% \mathrm{Al}_{2} \mathrm{O}_{3}, 5.9 \% \mathrm{Fe}_{2} \mathrm{O}_{3}, 2.3 \% \mathrm{~K}_{2} \mathrm{O}, 2.1 \% \mathrm{MgO}, 1.9 \% \mathrm{CaO}, 1.1 \% \mathrm{TiO}_{2}$, and $1.5 \% \mathrm{Na}_{2} \mathrm{O}$. A sodium metasilicate (SMS) granular powder under the trade name "Metso Beads 2048," supplied by the PQ Corporation was used as the alkali activator of Class F fly ash. Its chemical composition was 50.5 mol. wt\% $\mathrm{Na}_{2} \mathrm{O}$ and 46.6 mol. wt\% $\mathrm{SiO}_{2}$. Secar \#80, supplied by Kerneos Inc. was used as calcium aluminate cement (CAC). The X-ray powder diffraction (XRD) data showed that the crystalline compounds of Class $\mathrm{F}$ fly ash consisted mainly of quartz $\left(\mathrm{SiO}_{2}\right)$, mullite $\left(3 \mathrm{Al}_{2} \mathrm{O}_{3} \cdot 2 \mathrm{SiO}_{2}\right)$, and hematite $\left(\mathrm{Fe}_{2} \mathrm{O}_{3}\right)$, while CAC included three crystalline phases, corundum $\left(\alpha-\mathrm{Al}_{2} \mathrm{O}_{3}\right)$, calcium monoaluminate $\left(\mathrm{CaO} \cdot \mathrm{Al}_{2} \mathrm{O}_{3}, \mathrm{CA}\right)$, and calcium dialuminate $\left(\mathrm{CaO} .2 \mathrm{Al}_{2} \mathrm{O}_{3}, \mathrm{CA}_{2}\right)$.

The four solid retarders (Figure 1), oxalic acid (OA), D-(')-tartaric acid (TA), citric acid (CA), and boric acid (BA) were supplied by Sigma-Aldrich. In addition, the $37 \mathrm{wt} \%$ sodium silicate solution $\left(\mathrm{SiO}_{2} / \mathrm{Na}_{2} \mathrm{O}\right.$ mol. ratio of 2.50) as the trade name "STAR" was obtained from PQ Corporation for comparison purpose. 
<smiles>O=C(O)C(=O)O</smiles>

Oxalic Acid (OA)<smiles>O=C(O)C(O)C(O)C(=O)O</smiles>

Tartaric Acid (TA)

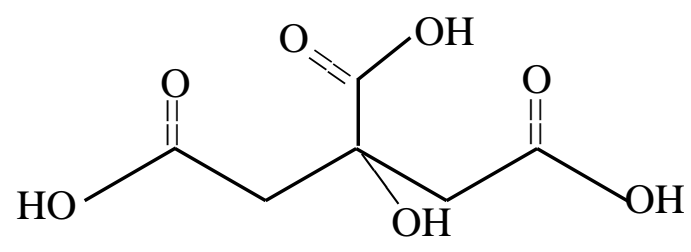

Citric Acid (CA)

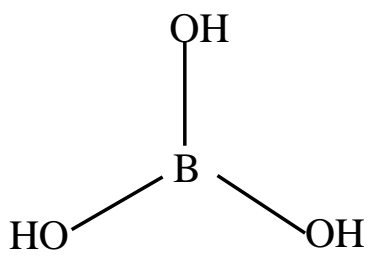

Boric Acid (BA)

Figure 1. Retarders tested in the study

Some tests were performed on foam slurries, for which the cocamidopropyl dimethylamine oxide-based foaming agent (FA) was provided by Halliburton under the trade name of "ZoneSealant 2000." An amount of $0.3 \%$ FA by total weight of water was added to the cement slurry to achieve a slurry density of around $1.3 \mathrm{~g} / \mathrm{cm}^{3}$.

We employed a dry blend cement formulation consisting of $60 \mathrm{wt} \%$ CAC and $40 \mathrm{wt} \%$ Class F fly ash. The sodium metasilicate was dry-blended with this mixture at $6.0 \%$ by total weight of the blend. The amounts of retarder used were $0.2-, 0.5-, 0.7-$, and $1.0-\%$ by total weight of this dry mixture. For our base slurries, the water-to-solid ratio was 0.52 , while for the foam slurries it was 0.55 . The latter were prepared in the following sequence: First, the water-miscible FA was blended in water; second, the FA-dispersed aqueous solution was added to a dry mixed-cement component consisting of SMS, CAC, fly ash, and retarder; consequently, the water/cement ratio for all of the retarder-containing foamed slurries was 0.55 ; and, finally, this cement slurry was mixed thoroughly for 30 seconds in a shear-blender, allowing us to prepare slurries with a vast number of air bubbles.

To measure the slurries compressive strength, they were cast into cylindrical molds (20 $\mathrm{mm}$ diam. and $40 \mathrm{~mm}$ long), and left to harden for 24 hours under a $100 \%$ relative humidity (R.H) at $85^{\circ} \mathrm{C}$. Then, some $85^{\circ} \mathrm{C}$-hardened cements were autoclaved at $200^{\circ}$ and $300^{\circ} \mathrm{C}$ for 24 hours under a pressure of $6.9 \mathrm{MPa}$.

\subsection{Measurements}

TAM Air Isothermal Microcalorimetry was used to obtain the normalized heat-flow curves during the hydration of the retarded cement slurries at $85^{\circ} \mathrm{C}$. The compressive strength was determined using the Electromechanical Instron System. Attenuated Total Reflectance-Fourier Transform Infrared Spectroscopy (ATR-FTIR) and X-ray powder diffraction (EDX) were used 
to identify the amorphous- and crystalline-reaction products, and also to define the crystalline phase transformations after autoclaving at an elevated temperature. We also used four analytical tools: Thermogravimetric Analysis (TGA) at the heating rate of $20^{\circ} \mathrm{C} / \mathrm{min}$ in a $\mathrm{N}_{2}$ flow; micro energy-dispersive X-ray ( $\mu \mathrm{EDX})$; TOC-L Total Organic Carbon Analyzer; and, Plasma Optical Emission Spectroscopy.

\section{Results and Discussion}

\subsection{Screening of Retarders}

We evaluated the retarding effect of SMS used for activating the fly ash in TSRC on the hydration of CAC. Figure 2 compares the heat flow curves for the water-, NaOH solution-, and SMS solution- CAC slurries. The CAC-water slurry (sample a) generated the maximum heat flow energy (MHFE) of $168 \mathrm{~mW} / \mathrm{g}$ at the top of the sharp narrow No.1 peak after only 13 minutes. The physical examination for CAC slurry at the end of the peak revealed that it had been converted into hard cement.

Interestingly, the value of MHFE evolved in the CAC hydrated in water strikingly diminished by 10.5 fold to $16 \mathrm{~mW} / \mathrm{g}$, during hydration in an SMS solution (sample c). The second broad peak (No. 2) appeared between $1 \mathrm{hr} 5 \mathrm{~min}$ and $19 \mathrm{hr} 28 \mathrm{~min}$. Shortly before the onset of the No.2 peak, we observed that CAC slurry remained fluid, but although the MHFE of the second peak was only $6 \mathrm{~mW} / \mathrm{g}$, the slurry was no longer mixable at the time of the peak's maximum. Since SMS forms two reactants in water, sodium hydroxide and ionic hydroxylated sodium silicate, as $\mathrm{Na}_{2} \mathrm{SiO}_{3}+2 \mathrm{H}_{2} \mathrm{O} \rightarrow \mathrm{NaOH}+\mathrm{Na}^{+}-\mathrm{OSi}(\mathrm{OH})_{3}$, the intriguing question was which reactant inhibits the hydration of CAC, decreasing heat flow and delaying the set. In resolving this question, we followed heat flow of $\mathrm{CAC}$ hydration in a $4.2 \% \mathrm{NaOH}$ solution. As is seen in Figure 2, although we observed some reduction of the MHFE compared with that of CAC-water system, the No.2 peak did not appear. Thus, $\mathrm{NaOH}$ did not effectively inhibit the hydration of CAC. In fact, we observed that the slurry set at the end of the heat peak, demonstrating that the ionic hydroxylated sodium silicate played the major role in delaying the hydration of the CAC slurry. Earlier studies recorded a strong retardation of CAC hydration by sodium silicate [11].

Figure 3 shows the effect of sodium silicate with low and high $\mathrm{SiO}_{2} / \mathrm{Na}_{2} \mathrm{O}$ ratios on heat flow during $\mathrm{CAC}$ hydration. Both silicates retarded the main heat peak of CAC cement. The higher the concentration of meta-silicate, the more delayed was the major hydration peak and smaller the maximum heat released. The effect of the high silicate ratio activator was much more dramatic than that of the meta-silicate. No heat flow was registered for more than 16 hours when $12 \%$ by weight of water (bwow) liquid silicate was added to the mix water. This result confirms strong retarding effect of polymerized $\left[\mathrm{SiO}_{2}\right]^{4-}$ ions on $\mathrm{CAC}$ hydration. 


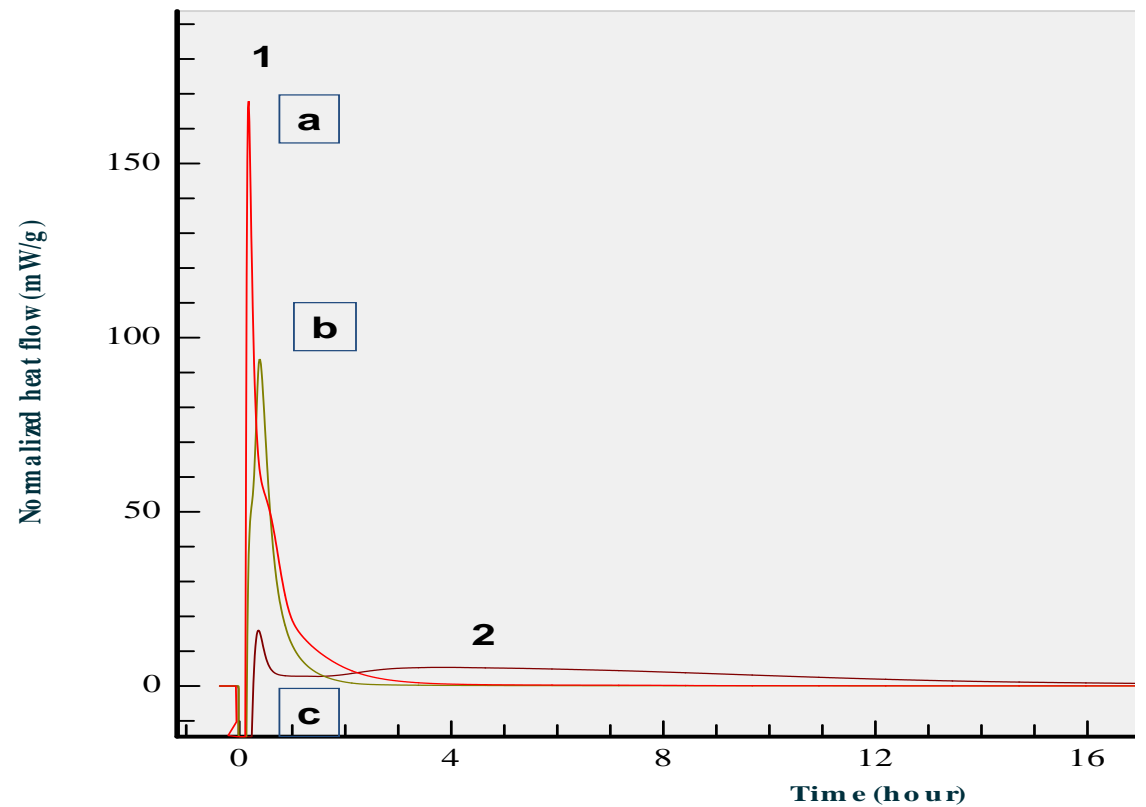

Figure 2. Normalized heat flow curves for (a) water-mixed CAC slurry; (b) $\mathrm{NaOH}$ solutionmixed CAC slurry; and (c) CAC slurry with SMS at $85^{\circ} \mathrm{C}$.

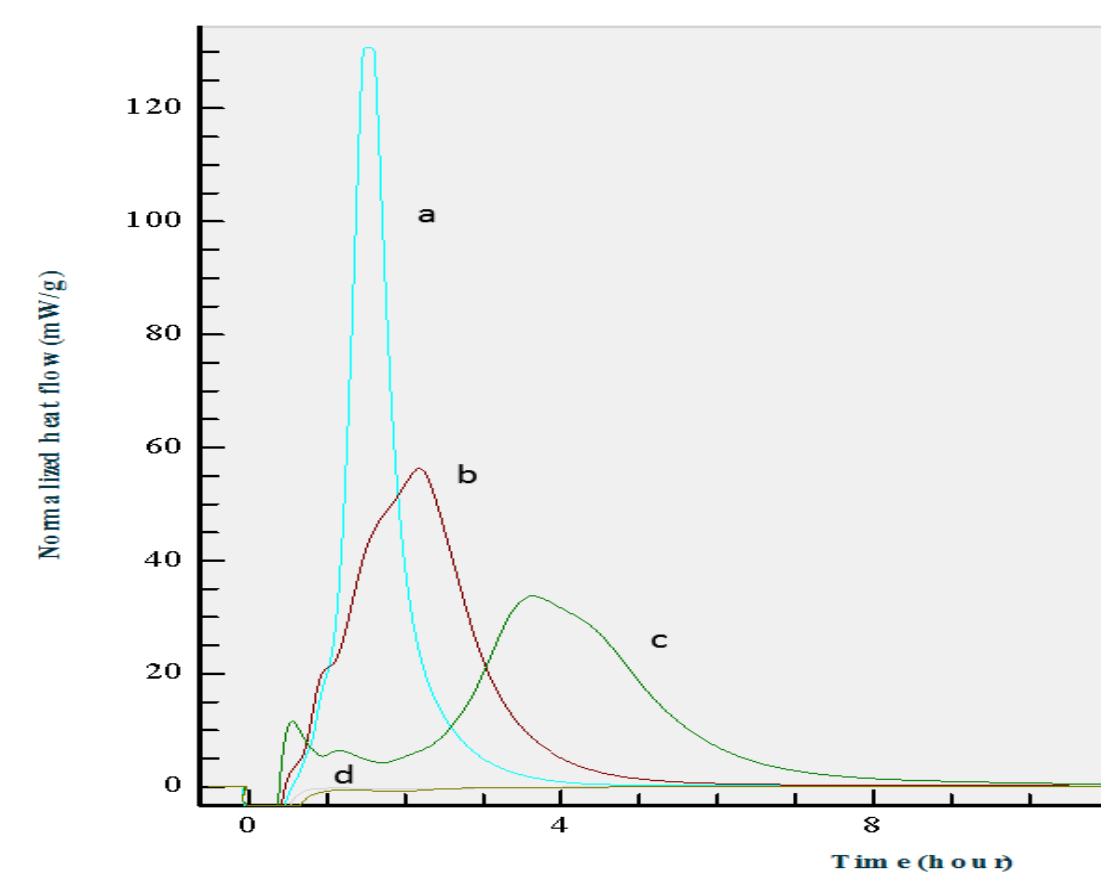

Figure 3. Normalized heat flow curves of CAC hydration with SMS [ $4 \%$ by weight of cement (bwoc) (a), $6 \%$ bwoc (b) and 8\% bwoc (c)] or polysilicate (STAR) (12\% by weight of water (d)) at $85^{\circ} \mathrm{C}$. 
We also looked at the effect of sodium silicate on the dissolution of fly ash. Figure 4 shows the two reference heat-flow curves from SMS dissolution in water (9 wt.\%) and fly ash in water (57 wt.\%) or a heat flow curve from fly ash mixed with SMS (57 wt\% fly ash, 9 wt \% SMS, and 34 wt $\%$ water). As expected, the water- fly ash sample (c) did not release any heat for eight and a half hours, and still was fluid when removed from the calorimeter, suggesting that no interaction occurred between the water and fly ash. Very little heat, if any, evolved from SMS solution (sample b). Although SMS dissolution is exothermic, it occurs so fast that the heat dissipates before the ampule comes into equilibrium with $85^{\circ} \mathrm{C}$-pre-heated calorimetric cell and heat-flow measurements begin. In contrast, there is a notable heat flow from the SMS-activated fly ash slurry due to the dissolution of fly ash with the concomitant breakage of the covalent bonds in $\mathrm{Si}-\mathrm{O}-\mathrm{Si}$ and Al-O-Al. In agreement with the literature, after the initial peak no heat was released associated with the accumulation of hydration products and structure condensation [15].

Nevertheless, the slurry was hard after 24 hrs.

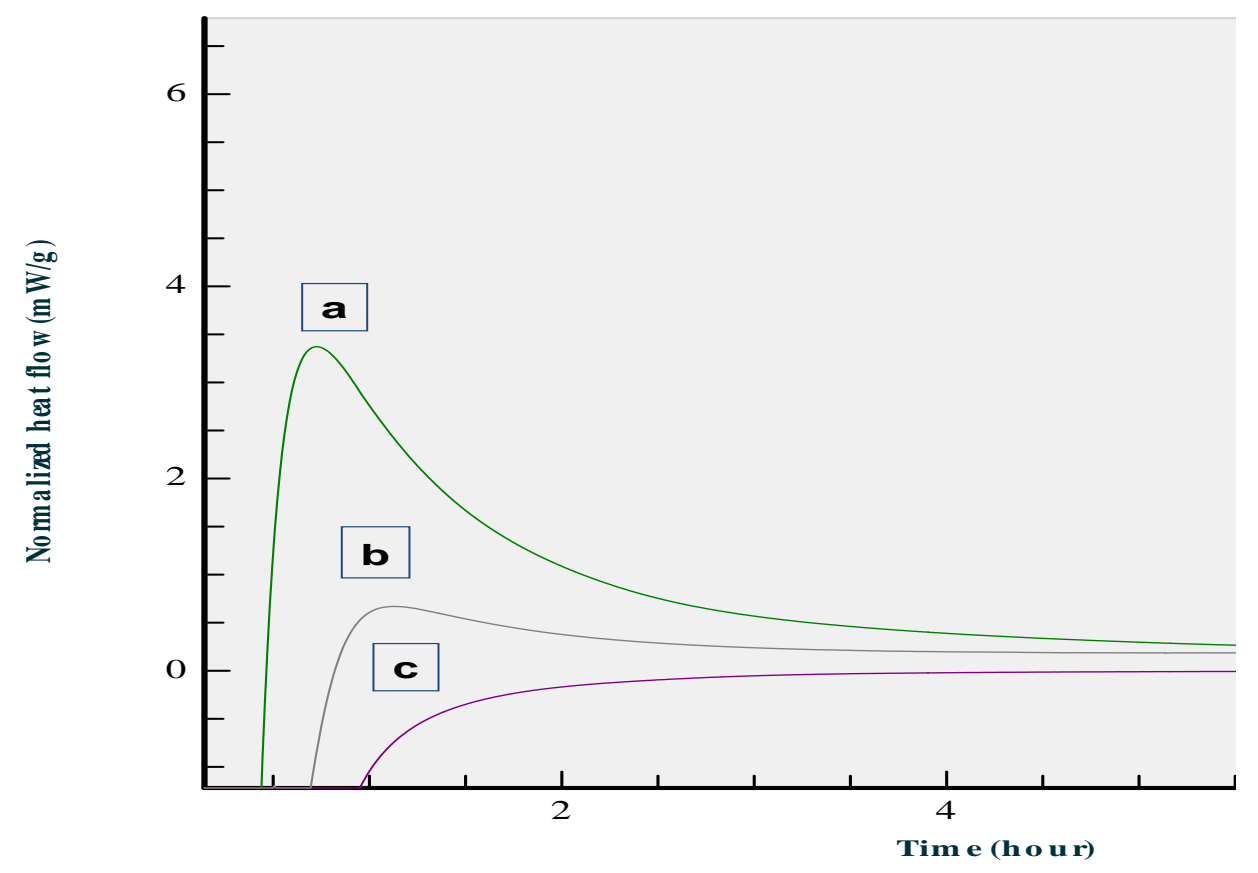

Figure 4. Normalized heat flow curves for SMS solution-activated Class F fly ash (a), SMS solution (b), and water-mixed Class F fly ash slurry (c) at $85^{\circ} \mathrm{C}$.

Figure 5 depicts the normalized heat flow curves of up to 44 hours TSRC hydration with 1.0 wt\% of citric- (CA) or tartaric-(TA) acids. The non-retarded slurry, denoted as the control, had three heat flow peaks: The first narrow peak, (No.1), emerged shortly after the ampoule with the slurry at room temperature was heated up to $85^{\circ} \mathrm{C}$ (about 40 minutes after introducing the ampoule into the calorimeter); the major peak came next (No. 2), followed by a shoulder peak (No. 3). The first peak involves initial wetting and dissolution of CAC and fly ash F in sodium silicate solution, the adsorption of some ions on to the solids and the formation of the primary reaction products [16-18]. In agreement with published data [15], our tests showed that there is only one initial heat-flow peak during the sodium-silicate activated dissolution of fly ash at $85^{\circ} \mathrm{C}$ (Figure 4). This information supports our reasoning that the major and the shoulder heat-flow 
peaks of the TSRC blend reflect the hydration of CAC. A recent study of the kinetics of hydration of monocalcium aluminate $(\mathrm{CA})$ and calcium di-aluminate $\left(\mathrm{CA}_{2}\right)$ suggests that the heat flow occurring during the main reaction of $\mathrm{CAC}$ is brought about primarily by $\mathrm{CA}$, while $\mathrm{CA}_{2}$ hydration starts as soon as the heat flow from CA hydration decreases [19]. Peak No.2 would represent CA hydration and peak No.3 $\mathrm{CA}_{2}$ hydration (Figure 5). The oven tests where fluidity of the slurry curing at $85^{\circ} \mathrm{C}$ was periodically tested with the spatula showed that the slurry kept its original fluidity at the onset point of peak No.2, stiffened at the time of the peak's maximum and was completely hardened by the end of the third peak; this point corresponds to the development of the cement's initial strength.

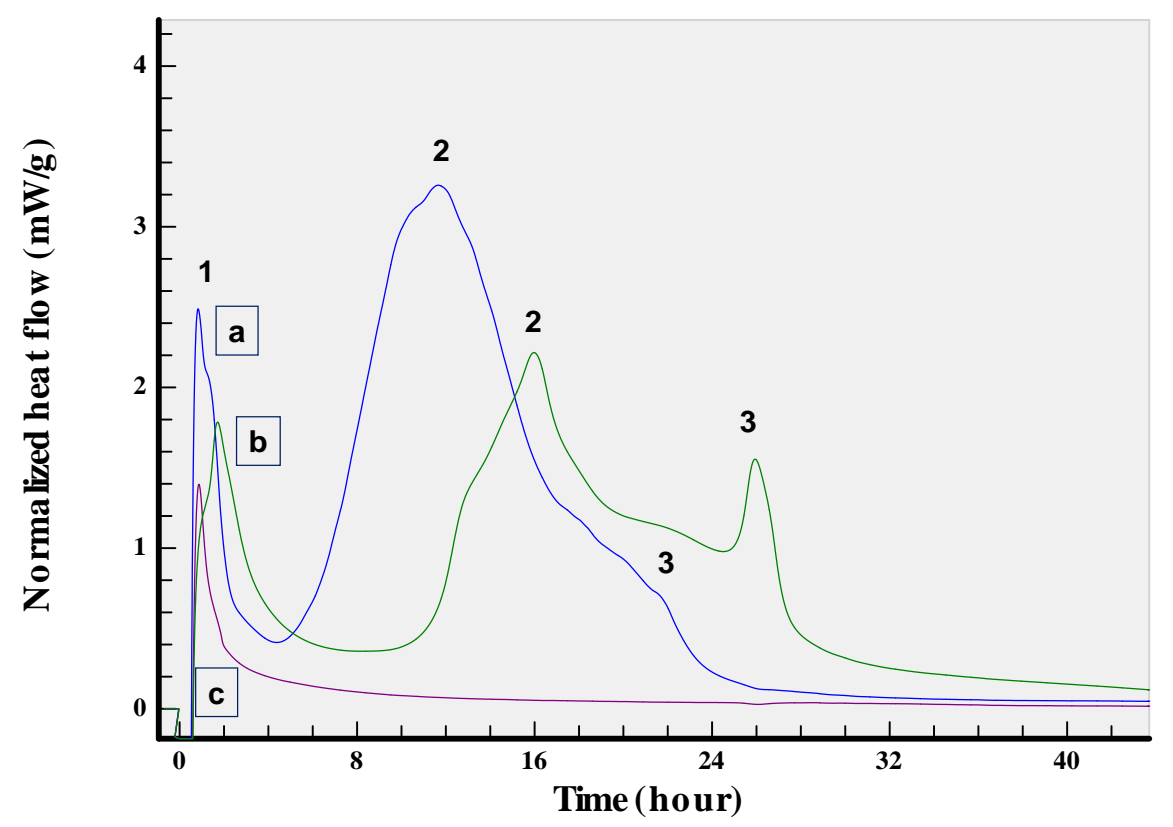

Figure 5. Normalized heat-flow curves for non-retarded, control, foam cement slurry (a), $1 \mathrm{wt} \%$ CA- (b), and TA- (c) retarded foamed slurries at $85^{\circ} \mathrm{C}$.

In the presence of $1 \%$ bwob CA, the value of MHFE of No.1 peak declined by $29 \%$ to 1.78 $\mathrm{mW} / \mathrm{g}$ from the $2.49 \mathrm{~mW} / \mathrm{g}$ of the control, the onset of No.2 peak shifted to $9 \mathrm{hr} 34 \mathrm{~min}$ from $4 \mathrm{hr}$ 19 min for the control; and an additional peak No.3 appeared. With $1 \%$ bwob TA, the heat flow curve had only one peak ( No.1) in 44 hours. The second peak emerged long after, at $96 \mathrm{hrs}$ (not shown). The onset of No. 2 peak occurred within 9 hrs for oxalic- and boric- acids (data not shown). Thus, in our calorimetric tests, TA was the most effective retarder at $1 \%$ bwob.

Figure 6 compares the heat flow curves from the control TSRC blend and the blends with $0.5 \%$ bwob TA and $0.7 \%$ bwob TA. Both the onset time of the major peak and the time of the heat peak maximum increased with the increase in concentration of tartaric acid. The onset times shifted to $11 \mathrm{hr} 22 \mathrm{~min}$ and $33 \mathrm{hr} 31 \mathrm{~min}$, respectively, for 0.5 and $0.7 \%$ bwob. Although retarded, the No. 3 peak became more prominent in the presence of tartaric acid. Again, we determined the time of slurry hardening by hand-mixing slurries cured in an $85^{\circ} \mathrm{C}$-oven at different time intervals. The results were similar to those of the control and $1 \% \mathrm{CA}$; namely, the 
slurry was still mixable at the onset time of No.2 peak, but no longer so at the time of the second peak of heat flow.

Based upon these tests, we estimated the setting times of slurries as the time of the intersection point of two linear extrapolations at the beginning of the No.2 peak. Figure 7 shows the setting times of TSRC with different retarders.

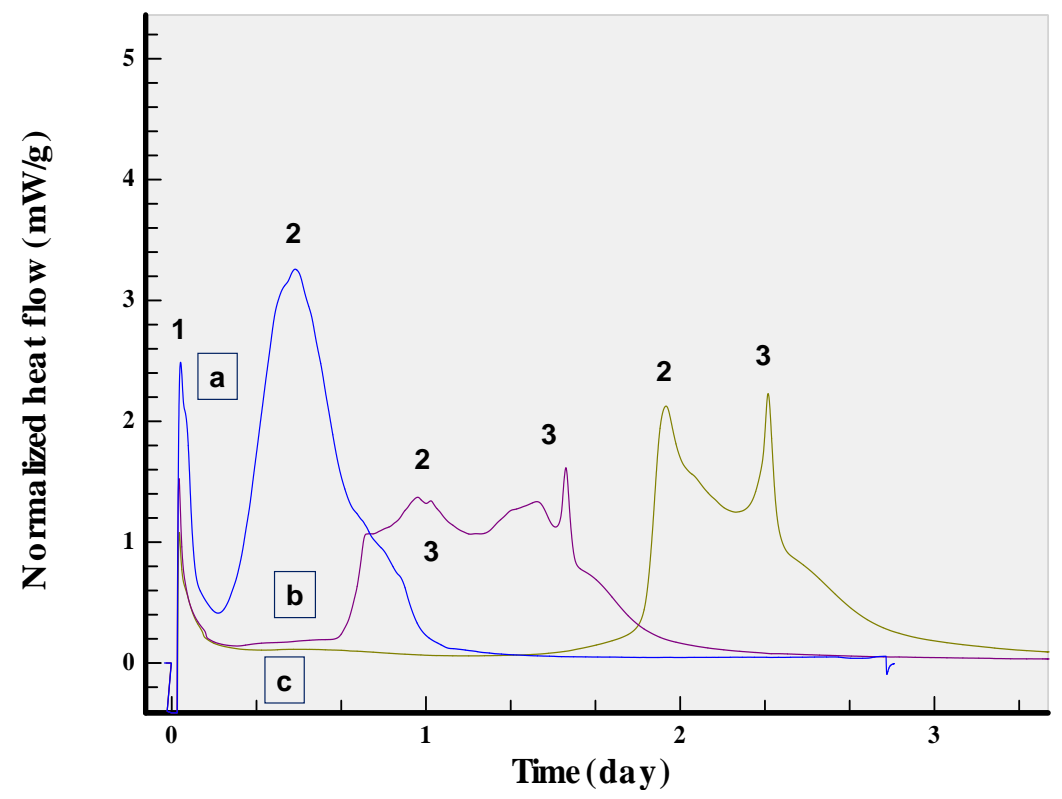

Figure 6. Comparison of the normalized heat-flow curves of control (a), and 0.5 (b) and $0.7 \%$ bwob TA-retarded foam cement slurries at $85^{\circ}$.

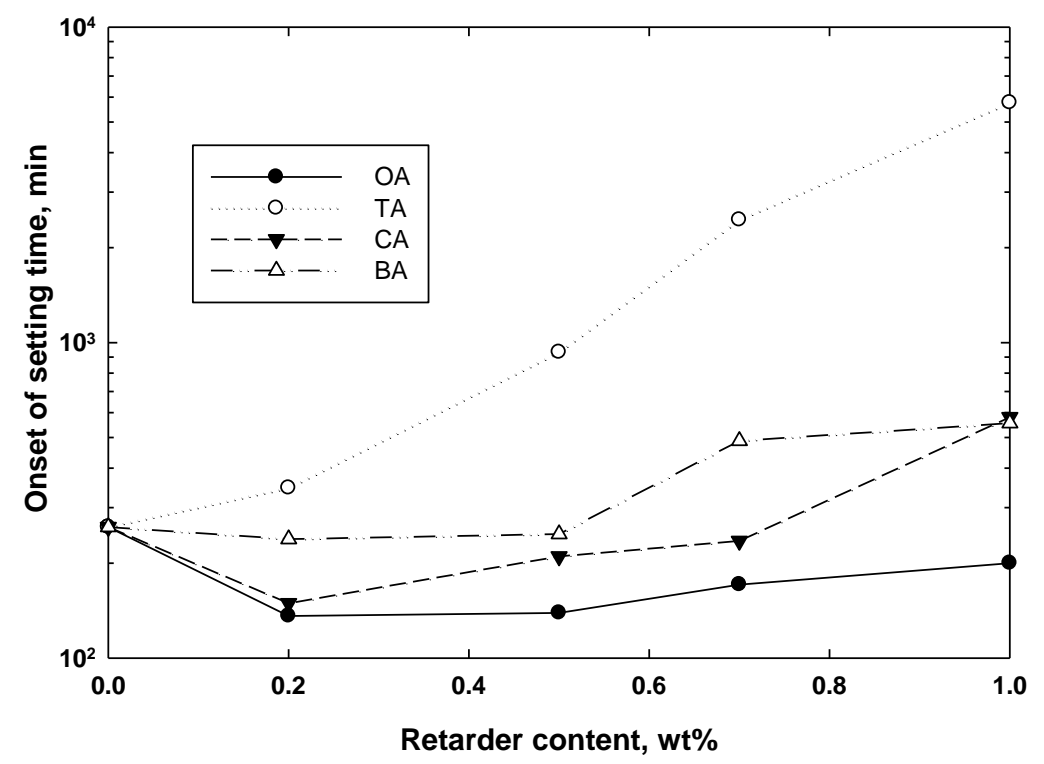


Figure 7. Setting times of TSRC at various concentrations of retarders measured in calorimetric tests at $85^{\circ} \mathrm{C}$.

The data demonstrate that both citric- and boric-acids mildly retarded the setting of cement, while oxalic acid slightly accelerated it. Among the retarders tested, only tartaric acid showed predictable increase in setting time with the increased concentration and long delays of cement set. Based on these calorimetric tests, TA was selected as the most effective retarder for SMSactivated $\mathrm{CAC} / \mathrm{Class} \mathrm{F}$ fly ash blend cement at $85^{\circ} \mathrm{C}$.

\subsection{Compressive strength}

We tried to evaluate whether the cumulative heat released in peaks No.2 and 3 correlates with the compressive strength developed by cement slurry after autoclaving for 24 hours at $85^{\circ} \mathrm{C}$ under pressure of $6.89 \mathrm{MPa}$. The cumulative heat in $\mathrm{J} / \mathrm{g}$, evolved in peaks No.2 and 3 was computed from the enclosed areas of the curve with the baseline made between onset of the No. 2 peak and the end of the No.3 peak (Figure 8). This heat declined as the content of the retarder rose, with the exception of oxalic acid that did not act as a retarder for the blend. The decrease was the most pronounced for $1 \%$ bwob TA-containing cement; the energy fell to $20 \mathrm{~J} / \mathrm{g}$, compared to against $92.4 \mathrm{~J} / \mathrm{g}$ of the control. Figure 9 illustrates the changes in compressive strength of cements with different retarders as a function of their concentration.

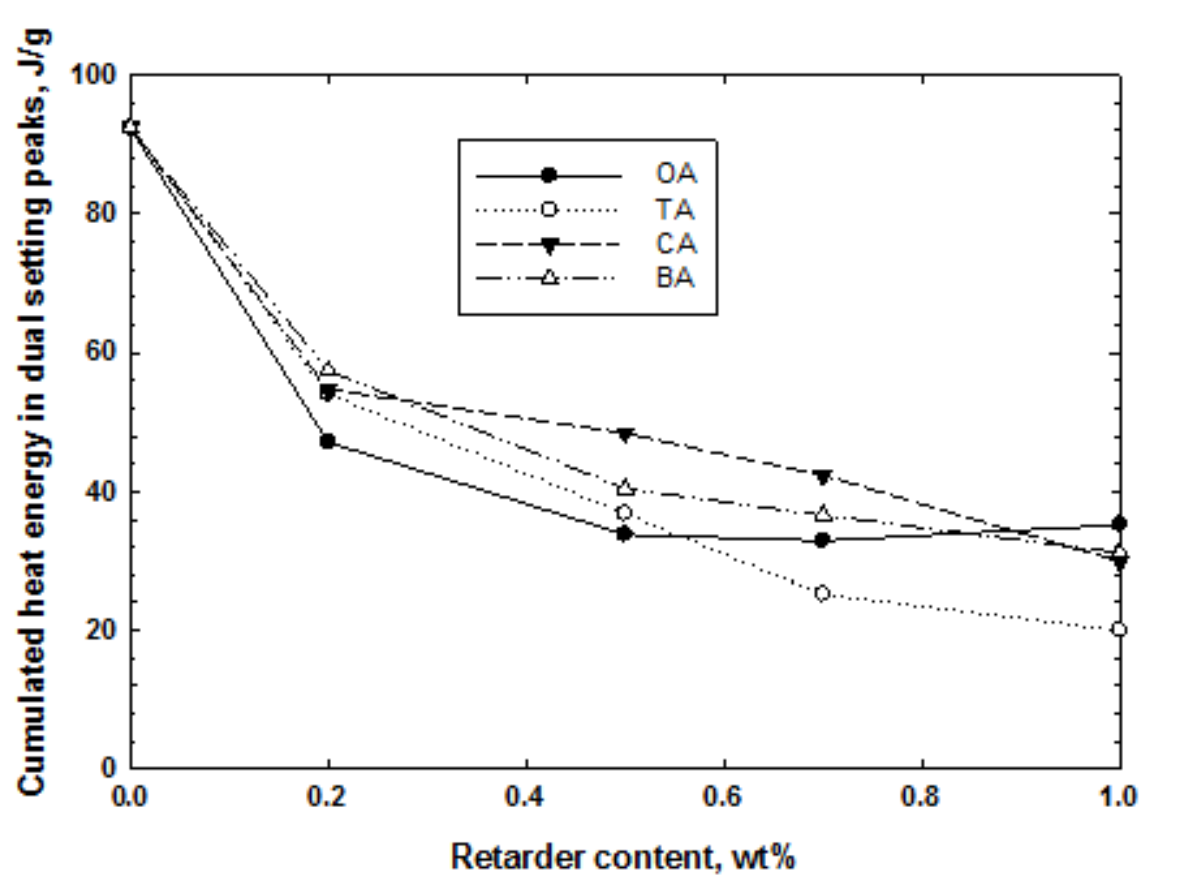

Figure 8. Changes in cumulative heat energy evolved in peaks 2 and 3 of various retardercontaining cement slurries as a function of the retarders' content.

The data revealed that concentrations of retarders up to $0.7 \%$ bwob did not greatly change the compressive strength of the cement. Thus, there was no direct correlation between the cumulated heat and compressive strength of the cured slurries. However, the $24 \mathrm{hr}$-curing time was not long enough for the cement to develop to full strength when the content of TA, CA, and BA was 
increased to $1 \%$. The compressive strengths of CA and BA-retarded blends were 1.4 and 2.0 $\mathrm{MPa}$, respectively, viz., 2.5- and 1.7-fold lower than that of the reference cement. With 1\% TA, the cement specimens were too weak for us to measure compressive strength.

Some samples cured at $85^{\circ} \mathrm{C}$ for $24 \mathrm{hrs}$ were further cured for $24 \mathrm{hrs}$ at $200^{\circ}$ and at $300^{\circ} \mathrm{C}$. The compressive strength of the non-retarded cement rose $45 \%$ and $106 \%$ to 4.8 - and $6.8-\mathrm{MPa}$ at $200^{\circ}$ and $300^{\circ} \mathrm{C}$, respectively (Figures $10-11$ ). The results were similar for all the retarded samples, implying that retarders do not change the compressive strength of cement cured for 24 hrs at $200^{\circ}$ and $300^{\circ} \mathrm{C}$.

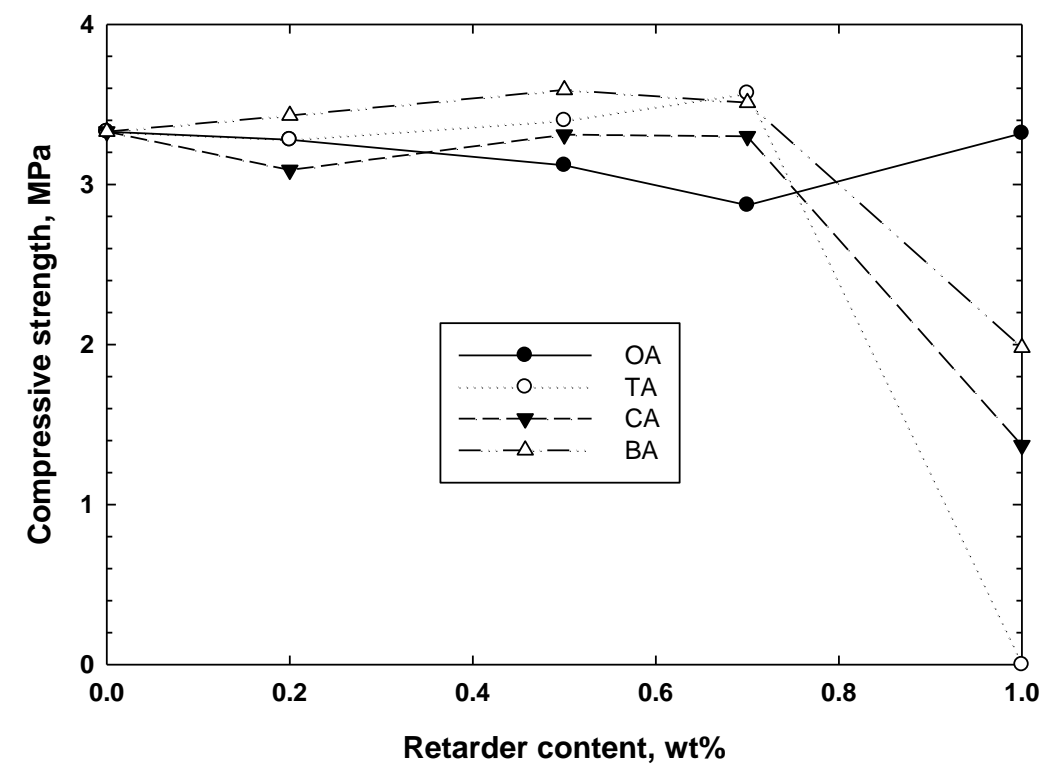

Figure 9. Changes in compressive strength of the $85^{\circ} \mathrm{C}-24 \mathrm{hr}-100 \%$ R.H cement modified with various retarders plotted as a function of the retarder's content. 


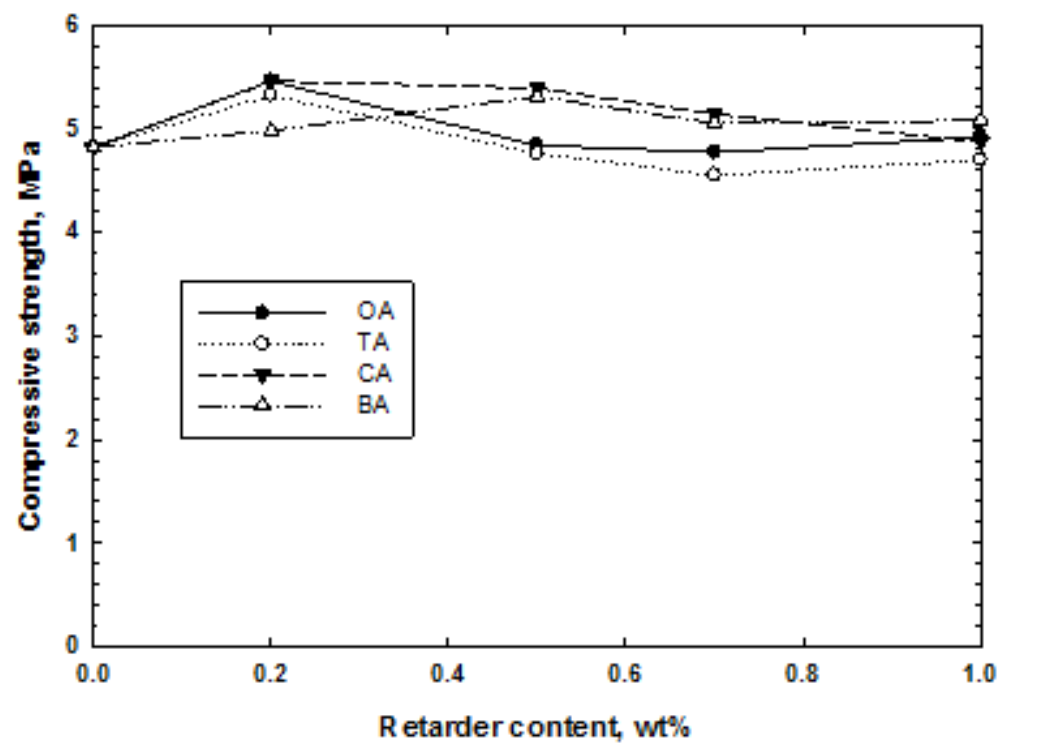

Figure 10. Compressive strength of $200^{\circ} \mathrm{C}-24 \mathrm{hr}$-autoclaved cements containing various retarders.

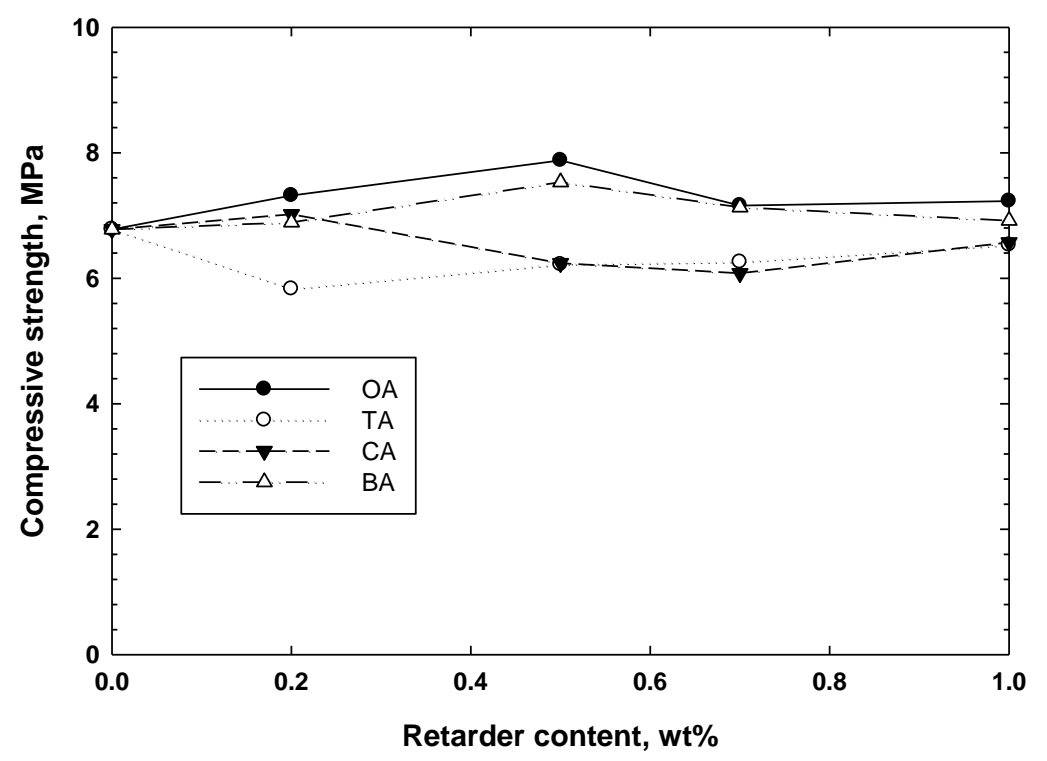

Figure 11. Compressive strength of $300^{\circ} \mathrm{C}-24 \mathrm{hr}$-autoclaved cements containing various retarders. 


\subsection{Role of TA in Controlling Cement Set}

We studied in more detail the setting retardation of the SMS-activated CAC/fly ash cement system (TSRC) by tartaric acid at $85^{\circ} \mathrm{C}$.

\subsubsection{Calorimetric and ART-FTIR studies}

We looked at the TA effect on the components of the TSRC cement using colorimetric tests. Figure 12 illustrates the heat-flow-time curves of TA-containing SMS/fly ash and fly ash without TA systems. As depicted, the MHFE value at No. 1 peak of SMS-activated fly ash (sample a) was reduced to nearly $3 \%$ by adding $0.5 \%$ TA by the total weight of fly ash (sample b). A further reduction to $15.7 \%$ was observed with $1.0 \% \mathrm{TA}$ (sample c), demonstrating that TA inhibited to some degree the interaction of fly ash with SMS. In contrast, fly ash was unsusceptible to the addition of TA. In fact, there was no heat flow peak in the 1.0\%TA/fly ash system without SMS (sample d). Thus, TA only interfered with the SMS-Fly ash reactions.

To identify possible reaction products between TA and SMS, we used a high amount of TA and prepared a solution containing $0.5 \mathrm{~g}$ TA, $0.5 \mathrm{~g}$ SMS, and $15.8 \mathrm{~g}$ water.

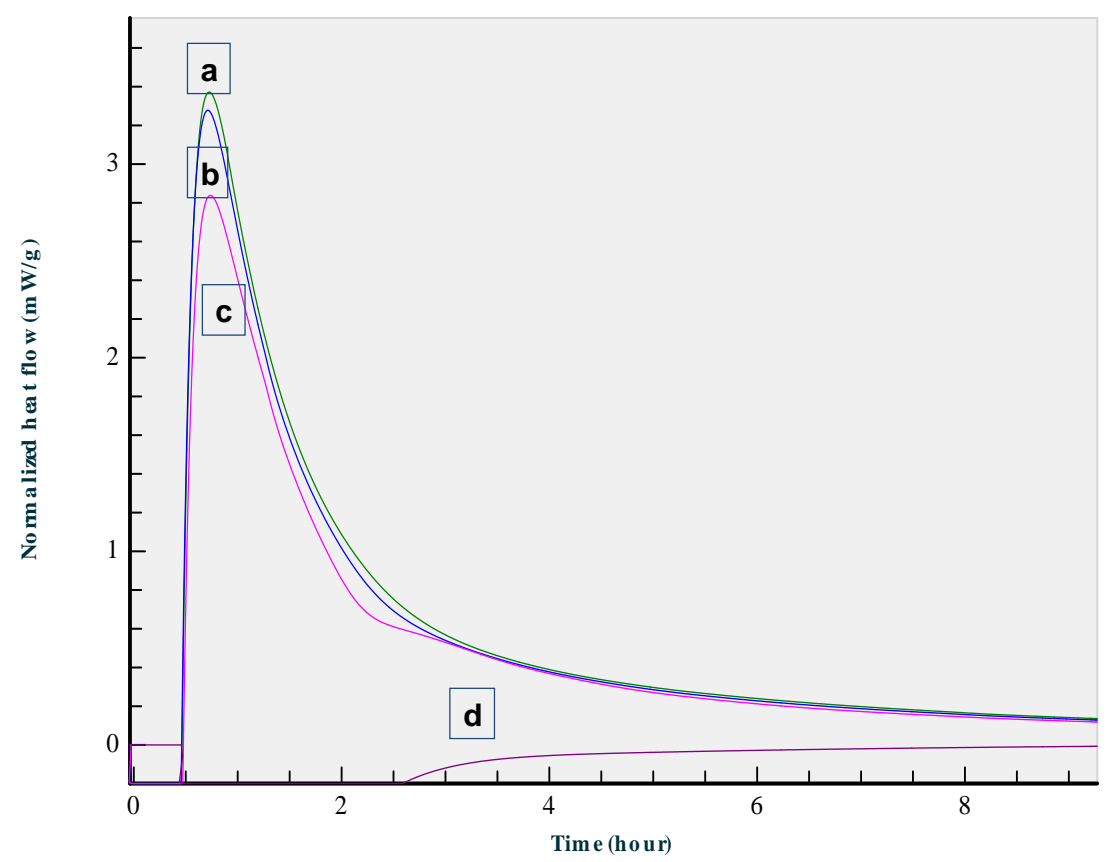

Figure 12. Heat flow curves for SMS solution-activated fly ash slurry (a), 0.5 (b) and 1.0 wt.\% TA (c)- SMS/fly ash slurries, and fly ash slurry with $1.0 \mathrm{wt} . \%$ TA (d).

We placed sealed containers with this solution into an oven at $85^{\circ} \mathrm{C}$ for 24 hours, and noted thereafter the precipitation of a gel from the solution; we separated it by centrifuging and dried it for $24 \mathrm{hr}$ at $85^{\circ} \mathrm{C}$ for ATR-FTIR analysis (Figure 13). For comparison, we prepared two references, TA and SMS alone, in the same manner. The AFT-IR spectrum of TA encompassed 
vibration bands attributed to six major bonds [20, 21]: One was the $\mathrm{C}=\mathrm{O}$ stretching vibration in carboxylic acid at $1734-$ and $1718-\mathrm{cm}^{-1}$; the second was associated with $\mathrm{O}-\mathrm{H}$ in-plane bending vibration at $1443-$ and $1393-\mathrm{cm}^{-1}$; the third was due to $\mathrm{C}-\mathrm{O}$ stretching in the acid, and ranged from 1361- to $1218-\mathrm{cm}^{-1}$; the fourth was associated with $\mathrm{C}-\mathrm{O}$ stretching related to the alcohol in the region between $1181-$ and $1085 \mathrm{~cm}^{-1}$; the fifth belonged to $\mathrm{O}-\mathrm{H}$ out-of-plane bending at 990 and $936-\mathrm{cm}^{-1}$ and, the sixth was the presence of $\mathrm{C}-\mathrm{H}$ bending in the region $1322-1127 \mathrm{~cm}^{-1}$. The spectrum of SMS had three prominent bands at 1429-, 932-, and $863-\mathrm{cm}^{-1}$, respectively attributed to the $\mathrm{CO}_{3}{ }^{2-}$ possibly in the sodium carbonate, the $\mathrm{Si}-\mathrm{O}$ stretching mode in non-oxygen bridged $\mathrm{SiO}^{-} \mathrm{Na}^{+}$group, and the $\mathrm{Si}-\mathrm{O}$ stretching in the silanol $\mathrm{Si}-\mathrm{OH}$ group [22]. The spectrum of the gel had four new bands at 1596-, 1394-, 1061-, and 796- $\mathrm{cm}^{-1}$. The contributors to all bands, except at $1061 \mathrm{~cm}^{-1}$, were the sodium tartrate, a reaction product of SMS and tartaric acid; namely, the two bands at 1596 - and $1394-\mathrm{cm}^{-1}$ were the $\mathrm{C}-\mathrm{O}$ asymmetric- and symmetric-stretching modes in the sodium carboxylate group, $-\mathrm{COO}^{-+} \mathrm{Na}$, while that at $796 \mathrm{~cm}^{-1}$ was due to the $\mathrm{Na}^{+--} \mathrm{O}$ linkage [2325]. There was no $\mathrm{C}=\mathrm{O}$ band in this spectrum related to the carboxylic acid, $\mathrm{COOH}$, group. Thus, the $\mathrm{COOH}$ in TA had reacted with the $\mathrm{NaOH}$ in the SMS solution at $85^{\circ} \mathrm{C}$ to form a sodium-tartrate salt.

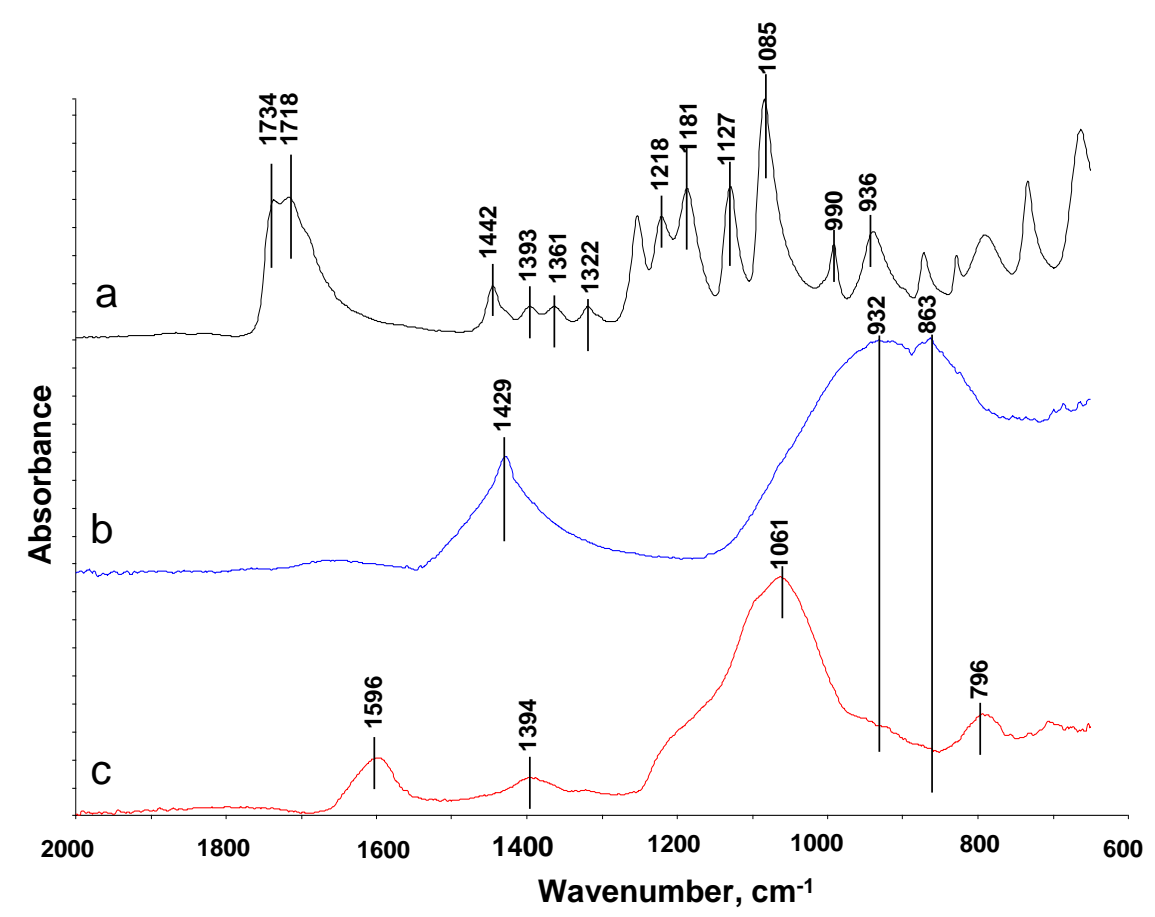

Figure 13. ART-FT-IR spectra, ranging from 2000 to640 cm-1, for TA (a), SMS (b), and gel (c) made by the reaction of TA with SMS in solution at $85^{\circ} \mathrm{C}$.

In fact, this reaction caused the decline of the $\mathrm{pH}$ of the SMS solution from 13.3 to10.5, reflecting the loss of the efficacy of SMS as an alkali activator of fly ash. This fact may explain why the MHFE of SMS-activated fly ash declined in the presence of TA. On the other hand, the new band that emerged at $1061 \mathrm{~cm}^{-1}$ was due to the Si-O stretching of the oxygen-bridged Si-OSi linkage [26, 27]. Further, this spectrum revealed a considerable decay of sodium carbonate-, $\mathrm{SiO}^{-} \mathrm{Na}^{+}$absorbance, and the complete disappearance of Si-OH-related absorbance. Relating this fact to the formation of the Si-O-Si linkage, we assumed that the reactions between TA and SMS 
not only led to the generation of sodium tartrate, but also promoted condensation reactions between the $\mathrm{OH}$ groups in hydroxylated sodium silicate to form a colloidal polysilicate made up of silicate chains, $\equiv \mathrm{Si}-\mathrm{O}-\mathrm{Si} \equiv$ (Figure 13 ).<smiles>CO[14CH2][14CH2][14CH2][14CH2]O[14CH2]O</smiles>

Tartaric acid (TA)

Hydrolysates of SMS<smiles></smiles>

Sodium tartrate $\quad$ Sodium polysilicate

Figure 14. Hypothetical reaction products formed by interactions between TA and the SMS solution at $85^{\circ} \mathrm{C}$.

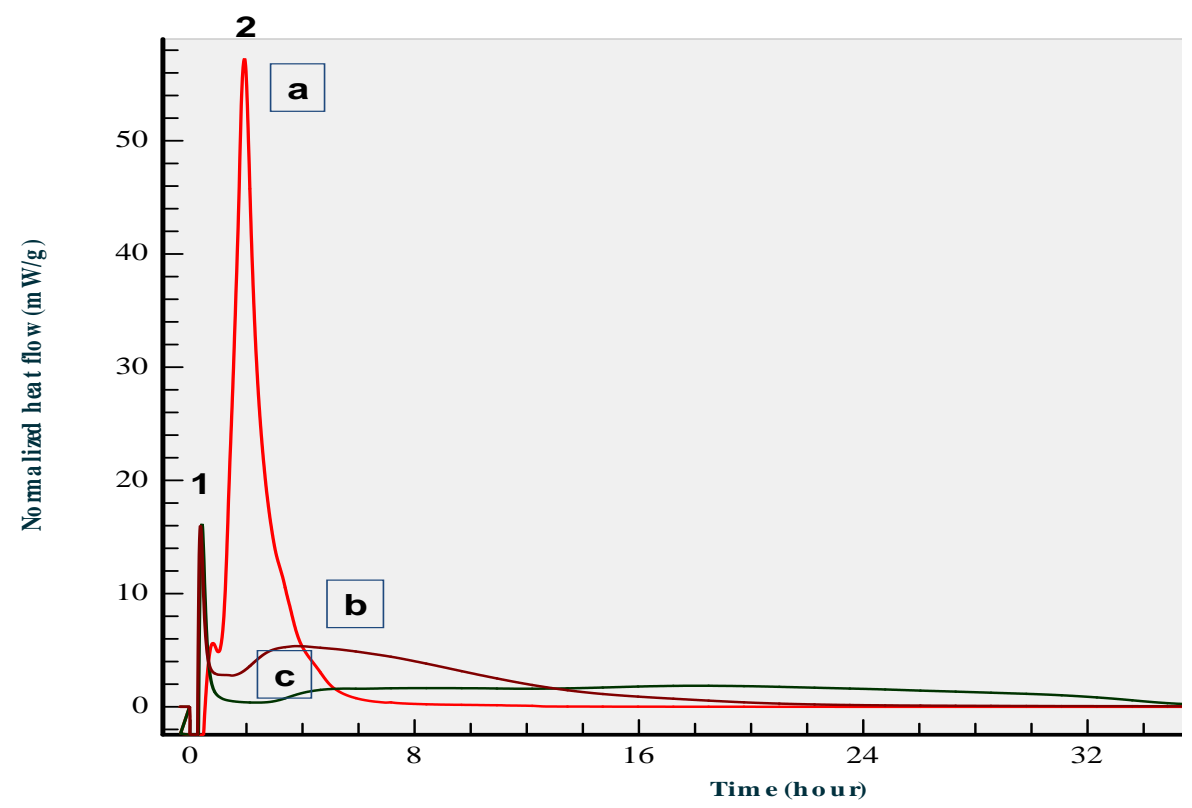

Figure 15. Normalized heat flow curves for CAC with0.5\% bwoc TA (a), CAC with SMS (b), and CAC with SMS and $0.5 \%$ bwoc TA (c). 
Figure 15 presents the heat-flow curves of CAC hydration alone, with SMS, and with both SMS and $0.5 \%$ bwoc TA. All these curves have two peaks. When $0.5 \%$ bwoc TA was incorporated into the slurry, the MHFE of peak No.1 was $5.6 \mathrm{~mW} / \mathrm{g}$, i.e., considerably lower than $168 \mathrm{~mW} / \mathrm{g}$ for the CAC/water system observed earlier without TA (Figure 2). In addition, a second CAC hydration peak appeared between $1 \mathrm{hr} 4$ minutes and $5 \mathrm{hr} 20$ minutes, suggesting that even a relatively low concentration of tartaric acid retards the hydration of calcium aluminate cement. Compared with this curve, the CAC/SMS system without TA had a strong No. 1 peak of 16 $\mathrm{mW} / \mathrm{g}$ MFHE, and broad No. 2 peak with $6 \mathrm{~mW} / \mathrm{g}$ MHFE. However, although the onset time of this No. 2 peak was similar to that in the CAC/0.5\% bwoc TA system, the TA extended the end time by TA 14 more hours. The combined TA-SMS system appeared to be more effective in inhibiting CAC hydration than did TA or SMS alone. The broad No.2 peak had the onset and end times of $2 \mathrm{hr} 51$ minutes and $36 \mathrm{hr} 2$ minutes respectively, and an MHFE of $1.9 \mathrm{~mW} / \mathrm{g}$.

To look for possible CAC-TA-SMS products, we prepared slurries with high contents of the reagents. The three CAC slurries prepared for the FT-IR analysis were 1) $0.5 \mathrm{~g} \mathrm{CAC}+0.5 \mathrm{~g}$ TA $+0.5 \mathrm{~g}$ water, 2) $0.5 \mathrm{~g} \mathrm{CAC}+0.5 \mathrm{~g} \mathrm{SMS}+0.5 \mathrm{~g}$ water, and, 3) $0.5 \mathrm{~g} \mathrm{CAC}+0.2 \mathrm{~g}$ (Figure 16). These samples were prepared as follows : First, $0.5 \mathrm{~g}$ water was added to the dry CAC/TA or /SMS mixture; second, the sealed containers with the mixtures were placed in an oven at $85^{\circ} \mathrm{C}$ for 24 hours; and, finally, the cured cements were dried at $85^{\circ} \mathrm{C}$ for $24 \mathrm{hrs}$.

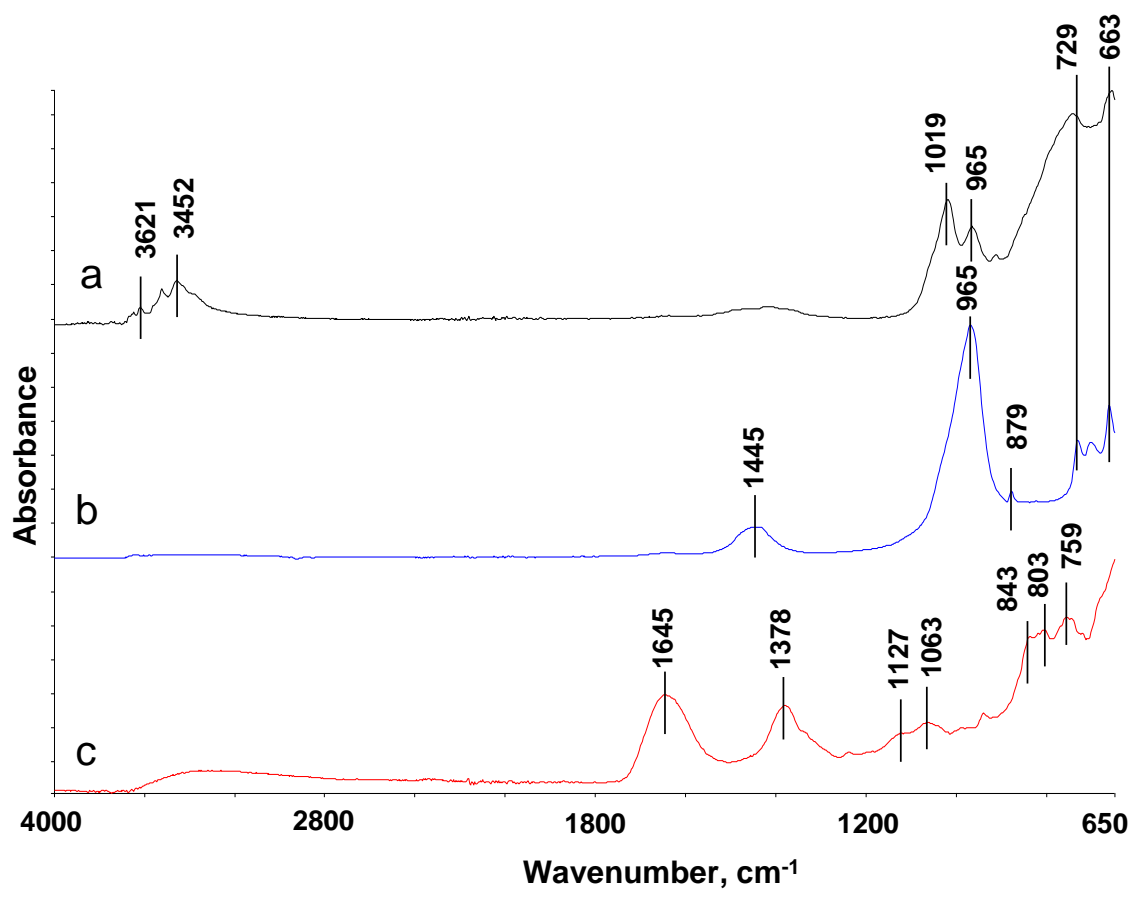

Figure 16. ART-FT-IR spectra for CAC hydrate (a), CAC in SMS solution (b), and TA-CAC hydrate (c).

The CAC/water system showed a typical spectrum of katoite, $\mathrm{Ca}_{3} \mathrm{Al}(\mathrm{OH})_{6}\left(\mathrm{C}_{3} \mathrm{AH}_{6}\right)$, and gibbsite, $\mathrm{Al}(\mathrm{OH})_{3}\left(\mathrm{AH}_{3}\right)$ phases [28, 29]; namely, this spectrum involved three distinctive vibration modes 
related to these phases, the $\mathrm{O}-\mathrm{H}$ stretching in $3621-3452 \mathrm{~cm}^{-1}$ region, $\mathrm{Al}-\mathrm{O}$ asymmetric stretching at $1019-$ and $965-\mathrm{cm}^{-1}$ bands, and Al-O-H bending at 729- and $663-\mathrm{cm}^{-1}$. We explain the spectrum of the CAC/SMS system as follows: Among the CAC-related bands were $\mathrm{CO}_{3}{ }^{2-}$ at the $1445 \mathrm{~cm}^{-1}$ band; Al-O at $965 \mathrm{~cm}^{-1}$; and, Al-O-H at 729- and $663-\mathrm{cm}^{-1}$; while we attributed the SMS-related bands at $1445-, 965-$, and $879-\mathrm{cm}^{-1}$ to the SMS-derived $\mathrm{CO}_{3}{ }^{2-}$ group, and -related $\mathrm{SiO}^{-+} \mathrm{Na}$ and $\mathrm{Si}-\mathrm{OH}$ groups, respectively. Compared with these spectral features, CAC/TA system developed three new bands at 1645-, 1378-, and 759- $\mathrm{cm}^{-1}$ belonging to the complexed carboxylate groups with the TA-associated bands at 1127-, 1063-, 843-, and 803- $\mathrm{cm}^{-1}$. When CAC comes in contact with water, the two major reactants in $\mathrm{CAC}, \mathrm{CA}$ and $\mathrm{CA}_{2}$, undergo hydrolysis, releasing two ionic species, $\mathrm{Ca}^{2+}$ and $\mathrm{Al}(\mathrm{OH})_{4}{ }^{-}$from $\mathrm{CA}$ and $\mathrm{CA}_{2}, \mathrm{CaO} \mathrm{Al}_{2} \mathrm{O}_{3}+$ $4 \mathrm{H}_{2} \mathrm{O} \rightarrow \mathrm{Ca}^{2+}+2 \mathrm{Al}(\mathrm{OH})_{4}^{-}$, and $\mathrm{CaO} \cdot 2 \mathrm{Al}_{2} \mathrm{O}_{3}+7 \mathrm{H}_{2} \mathrm{O}+2 \mathrm{OH}^{-} \rightarrow \mathrm{Ca}^{2+}+4 \mathrm{Al}(\mathrm{OH})_{4}^{-}$. Although the $\mathrm{Al}(\mathrm{OH})_{4}{ }^{-}$in a high $\mathrm{pH}$ environment releases $\mathrm{Al}^{3+}$ and $4 \mathrm{OH}^{-}$, since $\mathrm{CaO}$ has a higher solubility the calcium ions pass into the solution more readily leaving the surface richer in $\mathrm{Al}_{2} \mathrm{O}_{3}$ [19]. Hence, we considered that the $\mathrm{Ca}^{2+}$ was the source of cationic metal species in this carboxylate complex, forming calcium tartrate [30, 31].

From integrating this information, we derived the following hypothetical reaction pathways of TA in the SMS-activated CAC/fly ash system : Firstly, the COOH groups within TA reacted with $\mathrm{NaOH}$ dissociated from SMS to form sodium tartrate with a subsequent decrease in the slurry' $\mathrm{pH}$, whilst the SMS also formed an ionic sodium polysilicate species in the solution; secondly, the solution's decreased alkalinity partially suppressed the hydrolysis of fly ash, and simultaneously, ionic sodium polysilicate reacted with the surface of CAC grains, reducing the rate of CAC hydrolysis; thirdly, $\mathrm{Ca}(\mathrm{OH})_{2}$ derived from CAC dissolution also reacted with $\mathrm{COOH}$ in TA to yield two types of tartrate compounds (calcium-based and calcium/sodiumcombined, below); and, fourthly, these tartrate compounds also slowed down the hydration of FAF and CAC.<smiles>CC(C)(C)OC(=O)C(O)C(O)C(=O)O</smiles><smiles>[NH3+]OC(=O)C(O)C(O)C(=O)O[Ge]OC(=O)C(O)C(O)C(=O)O[Na]</smiles>

\subsubsection{Study of TSRC hydration with low concentrations of tartaric acid}

Studies with high TA concentrations helped identifying the reaction products of the retarder and cement-blend components. However, experiments with CAC and high amounts of TA showed 
that the acid accelerates cement set when added at concentrations above $1 \%$ bwoc, favoring some reactions and the formation of products that do not necessarily take place when the retarder is present at lower concentrations (Figure 17). Evidently, the integrated heat flow changes between the peaks (increases in the first, and decreases in the second) and new peaks appear as the acid concentrations increase between $1 \%$ and $4 \%$ bwoc.

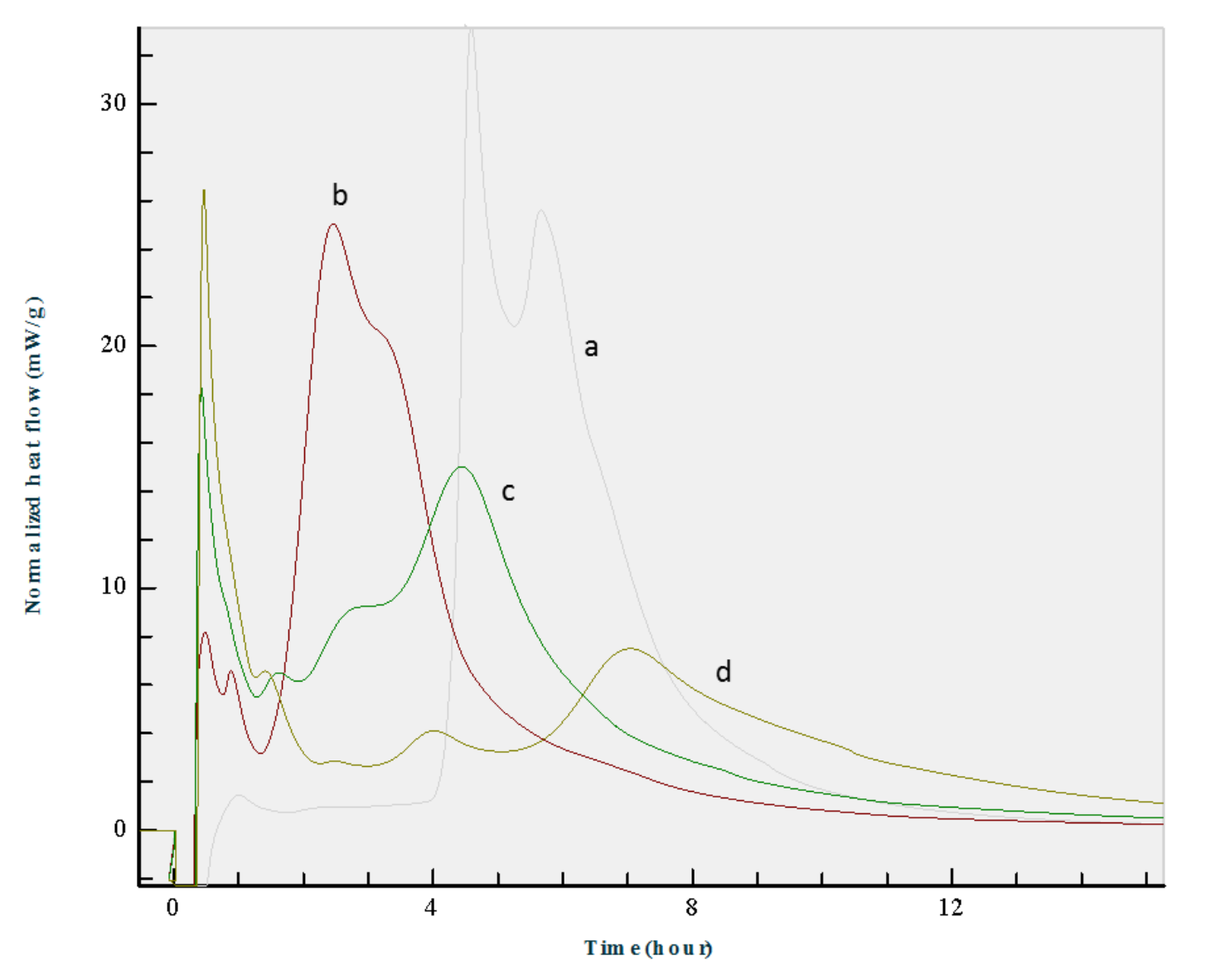

Figure 17. Normalized heat flow curves of CAC with $1 \%$ bwoc (a), $2 \%$ bwoc (b), $3 \%$ bwoc (c), and $4 \%$ bwoc (d) TA at $85^{\circ} \mathrm{C}$.

To comprehend the TA-TSRC interactions at lower retarder concentrations, we looked at the changes in the solid- and liquid-phases of TSRC hydrated at $85^{\circ} \mathrm{C}$ in the presence of $1 \%$ bwob TA. The samples were prepared in the following manner. The dry blends of TSRC (60/40 \#80/FAF with $6 \%$ bwob SMS) alone (control) or with $1 \%$ bwob TA were hand-mixed with water at blend-to-water ratio of 0.52 . Immediately thereafter, they were placed in an oven at $85^{\circ} \mathrm{C}$. After 1- or 2-hours of hydration, we removed the samples and centrifuged them at 6,000 rpm for 10 minutes. The separated liquid was filtered through $0.45 \mathrm{um}$ filter. The solid phase was dried in a vacuum oven at $85^{\circ} \mathrm{C}$ for 24 hours. The liquids were acidified with either nitric (for ICPOES) or hydrochloric acid (for TOC analyzer) and analyzed for calcium, silicon and organic carbon concentrations. The solids were analyzed with TGA-, $\mu$ EDX-, ATR-FTIR- and XRD- 
analyzers. We compared the solid phase compositions after these short hydration times against those obtained after 3 days of hydration at $85^{\circ} \mathrm{C}$. Table 1 summarizes the results for samples hydrated for 1 or 2 hours at $85^{\circ} \mathrm{C}$.

\subsubsection{Organic carbon in solution - TOC analysis}

As expected, the concentrations of organic carbon were higher in solutions from the samples retarded with tartaric acid. However, some organic carbon, likely from the fly ash, also was present in non-retarded samples. Its concentration declined both in retarded- and non-retardedsamples after 2 hours of hydration. Assuming that $1 \%$ bwob tartaric acid does not change the release of organic carbon from TSRC, we can estimate the amount of the retarder adsorbed on the solid as hydration proceeds. Only about $10 \%$ of the retarder is lost from the solution after the first hour of hydration and $33 \%$ after the second hour, signifying that during the first hours of hydration, most of the retarder stays in solution and its concentration decreases with time as hydration proceeds.

\subsubsection{Calcium and silicon in solution - ICP-OES analysis}

There were two major differences related to the concentration of calcium ions between solutions from retarded and non-retarded slurries: 1) Calcium concentration was more than two-fold higher after the first hour and almost 10-fold higher after the second hour of hydration in retarded slurry; 2) it declined almost 5-fold after the second hour of hydration in a solution from nonretarded slurry, and stayed almost constant in a solution from the slurry with $1 \%$ bwob tartaric acid. Silicon concentration in solution was slightly lower in the presence of tartaric acid (225 versus $238 \mathrm{mg} / \mathrm{L}$ for the slurry without it) after the first hour of hydration. After the second hour, the concentrations of both calcium and silicon dropped to low levels in the reference solution without tartaric acid (43- and 66-mg/L respectively) while remaining high in the presence of tartaric acid (425 mg/L Ca and $175 \mathrm{mg} / \mathrm{L} \mathrm{Si}$ ). The sharp decrease in calcium- and siliconconcentrations indicates the precipitation of some hydration products from non-retarded solutions, while, tartaric acid inhibited, at least partially, the formation of such hydrates during the first hours of hydration. The lower initial concentration of calcium without tartaric acid may be a result of the following scenarios - faster calcium dissolution with tartaric acid, faster precipitation of calcium-containing products in non-retarded slurries, or both. This is discussed further in the following sections.

The ICP-OES estimations of aluminum concentrations in solutions (data are not reported) showed roughly twice as much aluminum in the reference sample after the first hour of hydration as in the samples containing tartaric acid. 
Table 1. Analysis of TSRC samples hydrated for 2 hours at $85^{\circ} \mathrm{C}$ with or without $1 \%$ bwob tartaric acid

\begin{tabular}{|c|c|c|c|c|c|c|c|}
\hline $\begin{array}{l}\text { Hydration } \\
\text { time, } \mathrm{h}\end{array}$ & $\begin{array}{l}\text { Tartaric } \\
\text { acid, } \\
1 \% \\
\text { bwob }\end{array}$ & $\begin{array}{l}\text { TOC } \\
(g / L)\end{array}$ & $\begin{array}{l}\text { ICP-OES, } \\
\mathrm{mg} / \mathrm{L}\end{array}$ & $\mu \mathrm{EDX}, \%$ & $\begin{array}{l}\text { TGA, } \\
\text { Peak } \\
\text { temperature, } \\
{ }^{\circ} \mathrm{C}\end{array}$ & FTIR $^{*}$ & XRD \\
\hline \multirow[t]{2}{*}{1} & No & 1.2 & $\begin{array}{l}\text { Ca: } 205 \pm 1 \\
\text { Si: } 238 \pm 1\end{array}$ & $\begin{array}{l}\mathrm{CaO}: 18 \\
\mathrm{SiO}_{2}: 24 \\
\mathrm{Al}_{2} \mathrm{O}_{3}: 52\end{array}$ & $\begin{array}{l}112 \\
250 \\
292\end{array}$ & $968 \mathrm{~h} / \mathrm{b}$ & $\mathrm{NA}$ \\
\hline & Yes & 4.4 & $\begin{array}{l}\text { Ca: } 445 \pm 3 \\
\text { Si: } 225 \pm 1\end{array}$ & $\begin{array}{l}\mathrm{CaO}: 16 \\
\mathrm{SiO}_{2}: 26 \\
\mathrm{Al}_{2} \mathrm{O}_{3}: 51\end{array}$ & $\begin{array}{l}120 \\
248\end{array}$ & $\begin{array}{l}940 \mathrm{~h} / \mathrm{b} \\
1583 \mathrm{vl} / \mathrm{b} \\
1404 \mathrm{vl} / \mathrm{b}\end{array}$ & NA \\
\hline \multirow[t]{2}{*}{2} & No & 0.6 & $\begin{array}{l}\text { Ca: } \\
43.0 \pm 0.4 \\
\text { Si: } 66.0 \pm 1.2\end{array}$ & $\begin{array}{l}\mathrm{CaO}: 2- \\
12 \\
\mathrm{SiO}_{2}: \text { no } \\
\mathrm{Al}_{2} \mathrm{O}_{3}: \\
77-96\end{array}$ & $\begin{array}{l}217 \\
260 \\
298 \\
\text { shoulder }\end{array}$ & $\begin{array}{l}968 \mathrm{l} / \mathrm{b} \\
1404 \mathrm{vl} / \mathrm{b}\end{array}$ & $\begin{array}{l}\mathrm{C}_{3} \mathrm{AH}_{6}, \mathrm{AH}_{3} \text {, } \\
\text { non-reacted } \\
\text { CAC, FAF, } \\
\text { amorphous } \\
\text { phases }\end{array}$ \\
\hline & Yes & 3.0 & $\begin{array}{l}\text { Ca: } 425 \pm 2 \\
\text { Si: } 175 \pm 1\end{array}$ & $\begin{array}{l}\mathrm{CaO}: 19 \\
\mathrm{SiO}_{2}: 29 \\
\mathrm{Al}_{2} \mathrm{O}_{3}: 45\end{array}$ & $\begin{array}{l}112 \\
249\end{array}$ & $\begin{array}{l}959 \mathrm{~h} / \mathrm{b} \\
1583 \mathrm{l} / \mathrm{b} \\
1404 \mathrm{l} / \mathrm{b}\end{array}$ & $\begin{array}{l}\text { Non-reacted } \\
\mathrm{CAC} \text { and } \\
\mathrm{FAF}, \mathrm{C}_{3} \mathrm{AH}_{6} \text {, } \\
\text { amorphous } \\
\text { phases }\end{array}$ \\
\hline
\end{tabular}

*H/b - high/broad; vl/b - very low/broad; 1/b - low broad

\subsubsection{Solid phase - FTIR analysis}

All FTIR spectra of solid samples hydrated for 1- or 2-hours showed high peak-shoulders just below the peaks at $\sim 1000 \mathrm{~cm}^{-1}$. These peaks of some $\left(\mathrm{SiO}_{4}\right)^{4-}$, replaced by $\left(\mathrm{AlO}_{4}\right)^{3-}$, were at a slightly lower wavenumber for slurries with tartaric acid $\left(940\right.$ and $959 \mathrm{~cm}^{-1}$ for 1 and 2 hours of hydration respectively versus $968 \mathrm{~cm}^{-1}$ without tartaric acid). The lower wavenumber suggests a higher substitution with aluminum [15] for the case of tartaric acid. Two low broad peaks at 1583 - and $1404-\mathrm{cm}^{-1}$ assigned to asymmetric and symmetric (COO) stretching grew as hydration with the acid proceeded. The shift of asymmetric $\mathrm{COO}$ band to 1583 from a higher wavelength 
and its separation from the symmetric band by about $200 \mathrm{~cm}^{-1}$ points to a monodentate coordination of the carboxylate group [32]. The broad peak at $1583 \mathrm{~cm}^{-1}$ is assigned to calcium, sodium, and/or aluminum salts of tartaric acid. The broadness of the peak indicates that there is a mixture of components in different conformations. Only the peak at $1404 \mathrm{~cm}^{-1}$ appeared after two hours of hydration in specimens without the retarder (Figure 18).

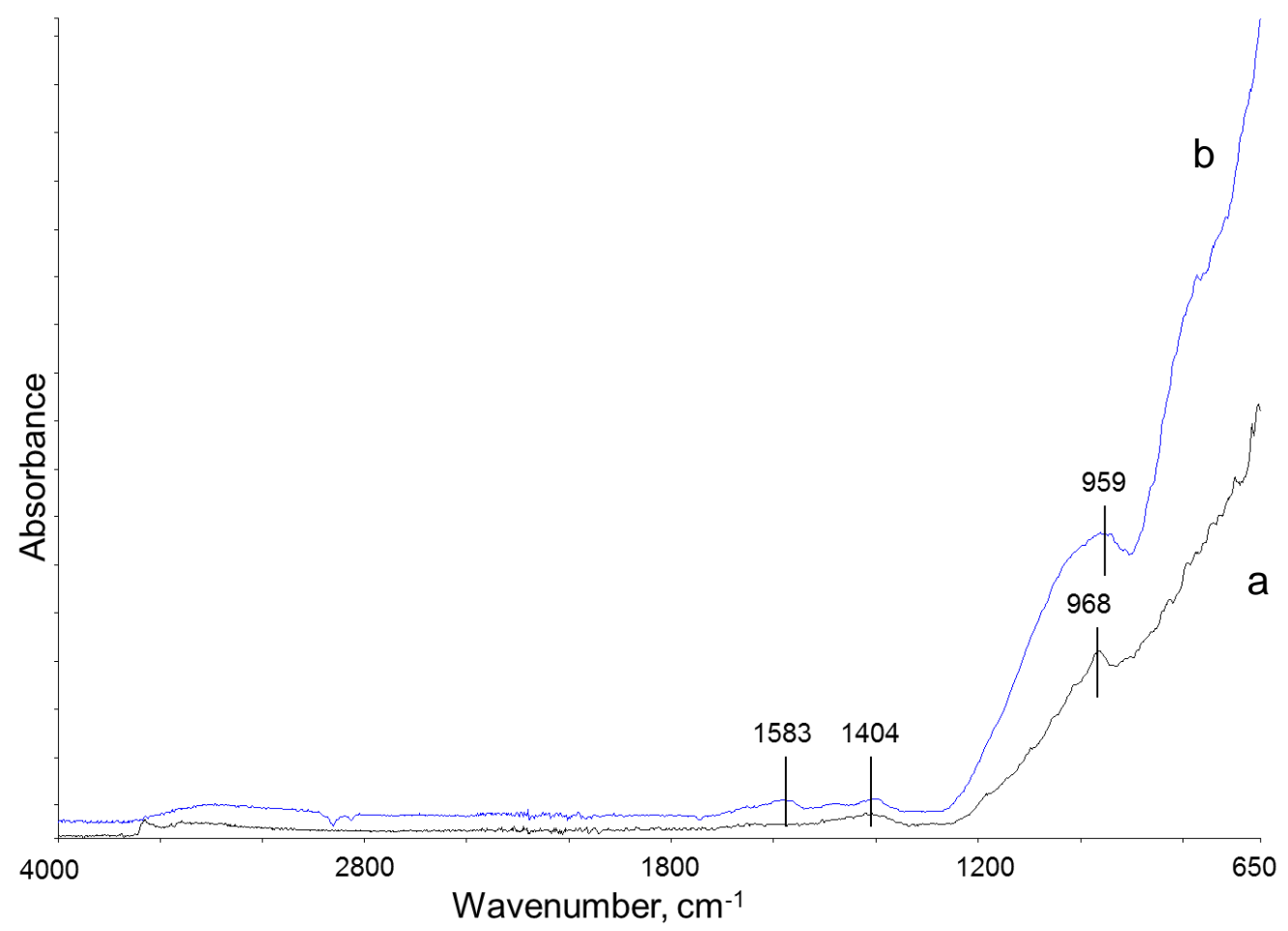

Figure 18. ATR-FT-IR spectra for TSRC hydrated for 2 hours at $85^{\circ} \mathrm{C}$ without (a), or with $1 \%$ bwob TA (b).

A thin layer of a white colloidal precipitate appeared after centrifuging the slurries with $1 \%$ bwob tartaric acid. We collected it and studied it via FTIR and EDX.

The FTIR spectra of the precipitate revealed two big peaks from carboxylate [-COO]symmetric- and asymmetric-stretching at 1396 and a split peak at 1600 and $1564 \mathrm{~cm}^{-1}$ respectively (Figure 19). The band separation suggests that they represent the monodentate complexes of tartaric acid as explained above. The split of the second peak indicates the formation of carboxylates with different cations. A similar $\mathrm{H}-\mathrm{O}-\mathrm{H}$ split peak also was observed by Palomo et al. [15] upon activating fly ash with sodium silicate. We assigned a high peak at $970 \mathrm{~cm}^{-1}$ to the asymmetric stretching of Si-O-Si and Al-O-Si in an aluminosilicate network [33] while a split peak between 1130 - and $1092-\mathrm{cm}^{-1}$ - reflected the Si-O and Al-O vibrations. The peaks below $800 \mathrm{~cm}^{-1}$ that were related to aluminum- and silicon-compounds were not well resolved. The peaks between 3600 - and $2800-\mathrm{cm}^{-1}$ were associated respectively with water and the hydroxyl ion. Accordingly, the findings from our FTIR study suggest the presence of 
monodentate, mixed-cation complexes of tartaric acid, and possibly their precipitation as hydration proceeds, along with high aluminum substitution in the silicon-oxygen chains in the presence of the retarder. (Note that the precipitation also could result from the cooling of the slurry during centrifugation.)

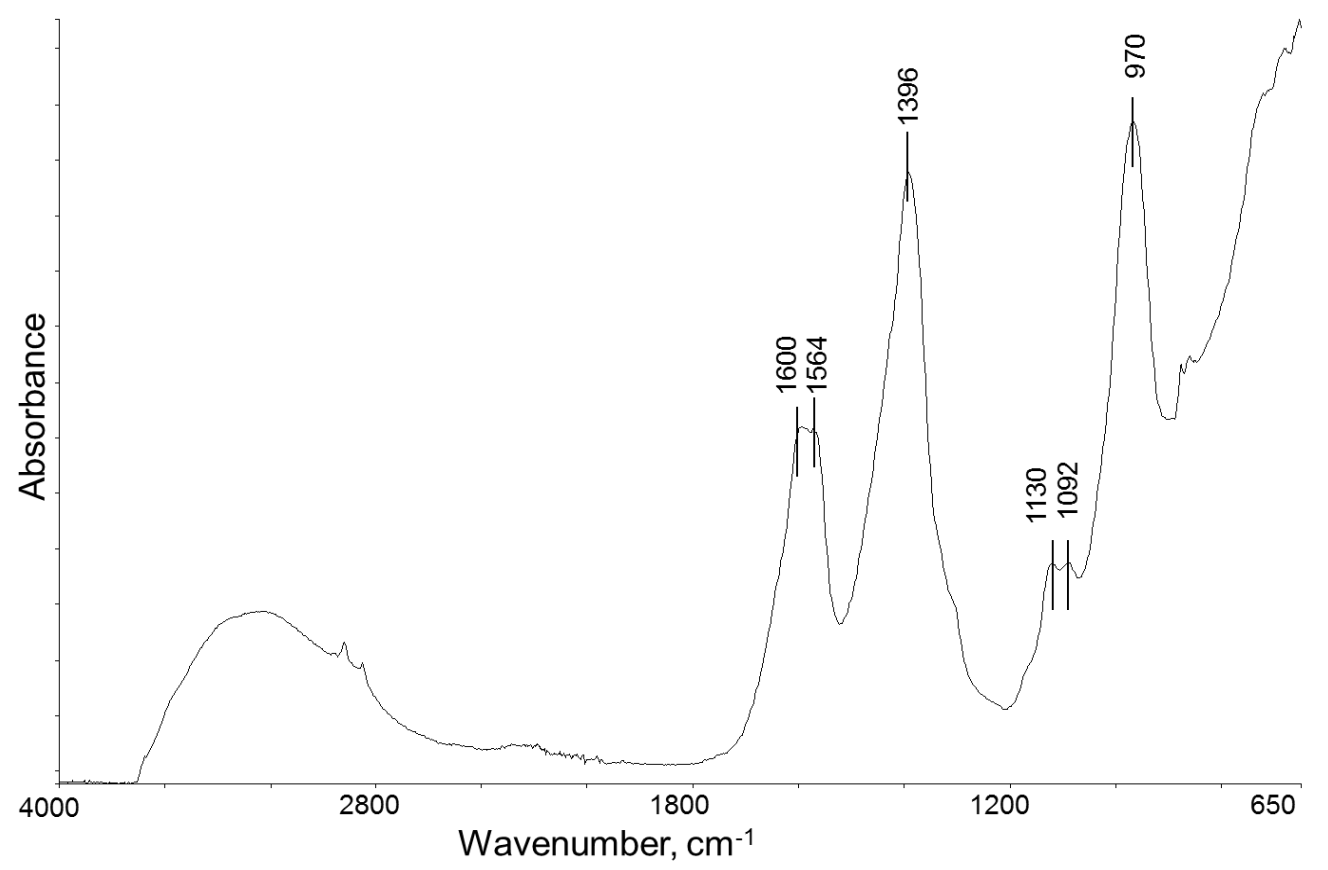

Figure 19. ATR-FTIR spectra for a white precipitate collected from the TSRC blend hydrated for 1 hour with $1 \%$ bwob TA.

\subsubsection{Solid phase-TGA- and XRD-analyses}

These two techniques coherently revealed the formation of stable katoite $\left(\mathrm{C}_{3} \mathrm{AH}_{6}\right)$ and gibbsite $\left(\mathrm{AH}_{3}\right)$ for a non-retarded cement sample after 2 hours of hydration and mostly amorphous hydration products along with the non-hydrated starting materials for the retarded samples.

Figure 20 compares the TGA curves of samples retarded with tartaric acid against one sample without tartaric acid after 1 hour of hydration. All thermograms have broad peaks at about $120^{\circ} \mathrm{C}$, which likely are due to poorly crystallized sodium alumosilicate hydrates from the reaction of fly ash with sodium silicate [13]. This peak is more prominent in retarded samples than in those without tartaric acid. The contribution of water to the peak is unlikely since the samples were dried before the test and the peak decreased at longer hydration times. The reference, a non-retarded sample, exhibited a weight loss at $250-260^{\circ} \mathrm{C}$ associated with the gibbsite [34] along with a weight loss at about $300^{\circ} \mathrm{C}$ from katoite. As hydration proceeds, this peak is overcome by the gibbsite peak and becomes simply a shoulder on the bigger peak of gibbsite (data not shown). This finding concurs with the XRD patterns of the non-retarded sample after 2 hours, which are dominated by gibbsite, whilst the katoite peaks also are present 
(Figure 21). The bigger weight loss at $300^{\circ} \mathrm{C}$ than at $260^{\circ} \mathrm{C}$ points to the initial presence of $\mathrm{C}_{3} \mathrm{AH}_{6}$ on the surface of the solid phase after 1 hour of hydration, followed by a massive precipitation of $\mathrm{AH}_{3}$, which becomes a major hydration product after 2 hours.

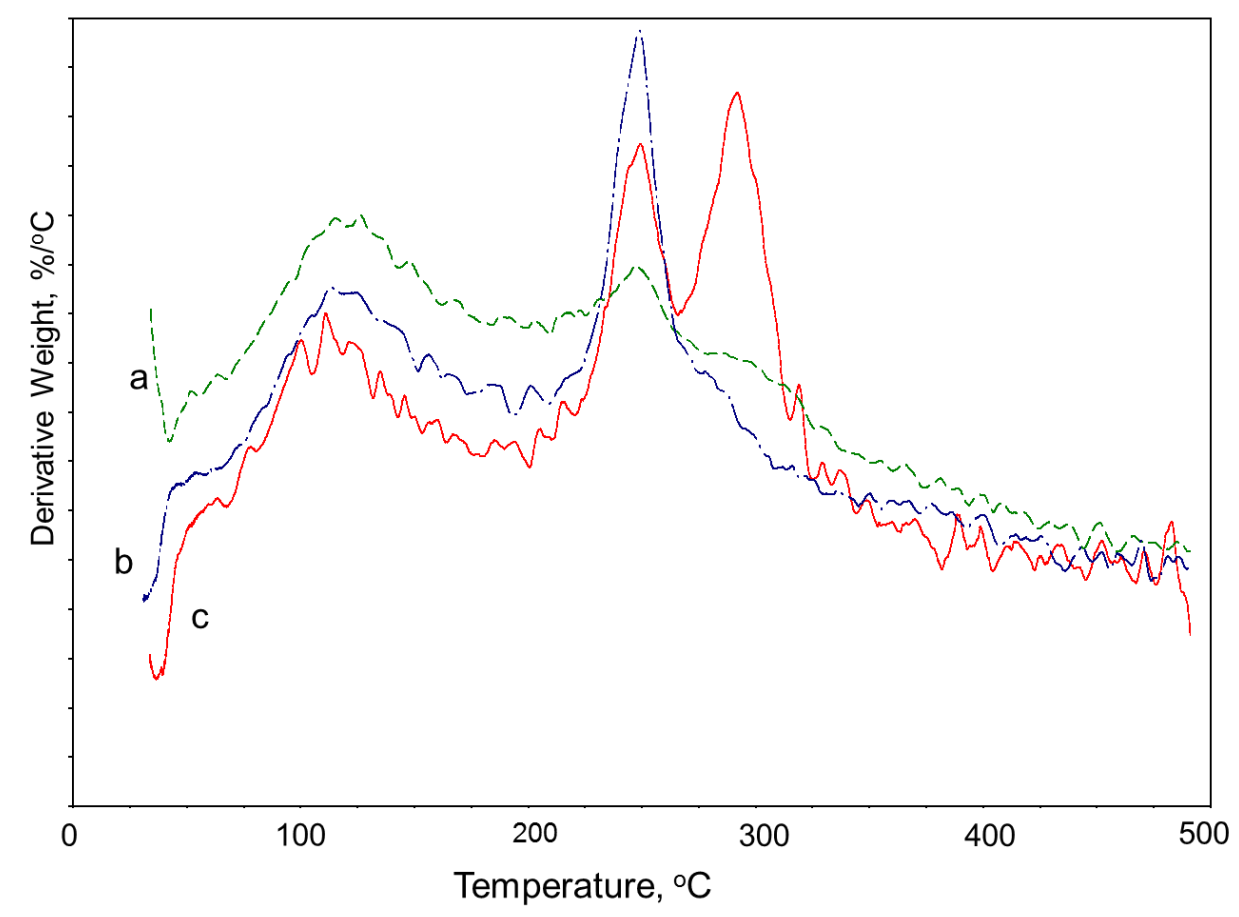

Figure 20. Derivative TGA curves for TSRC cement hydrated with $1 \%$ bwob TA for 1 hour (a), 2 hours (b), or without TA for 2 hours (c).

The gibbsite decomposition peak initially is small but grows with hydration time for samples with $1 \%$ tartaric acid. Gibbsite, revealed by TGA, is amorphous since no crystalline peaks appear on the XRD pattern. There are only small peaks of $\mathrm{C}_{3} \mathrm{AH}_{6}$ after 2 hours of hydration in the presence of tartaric acid. The decomposition temperatures of katoite and gibbsite formed when tartaric acid is present are lower than in samples without retarders (Table 1), indicating their lower crystallinity.

The TGA- and XRD-studies show that tartaric acid efficiently inhibits the crystallization of katoite and slows down the formation of amorphous gibbsite in the first couple of hours of hydration. In agreement with data in the literature $[35,36]$ no intermediate calcium aluminate hydrates are formed at $85^{\circ} \mathrm{C}$; rather, hydration proceeds directly to the formation of katoite and the crystallization and precipitation of gibbsite. 

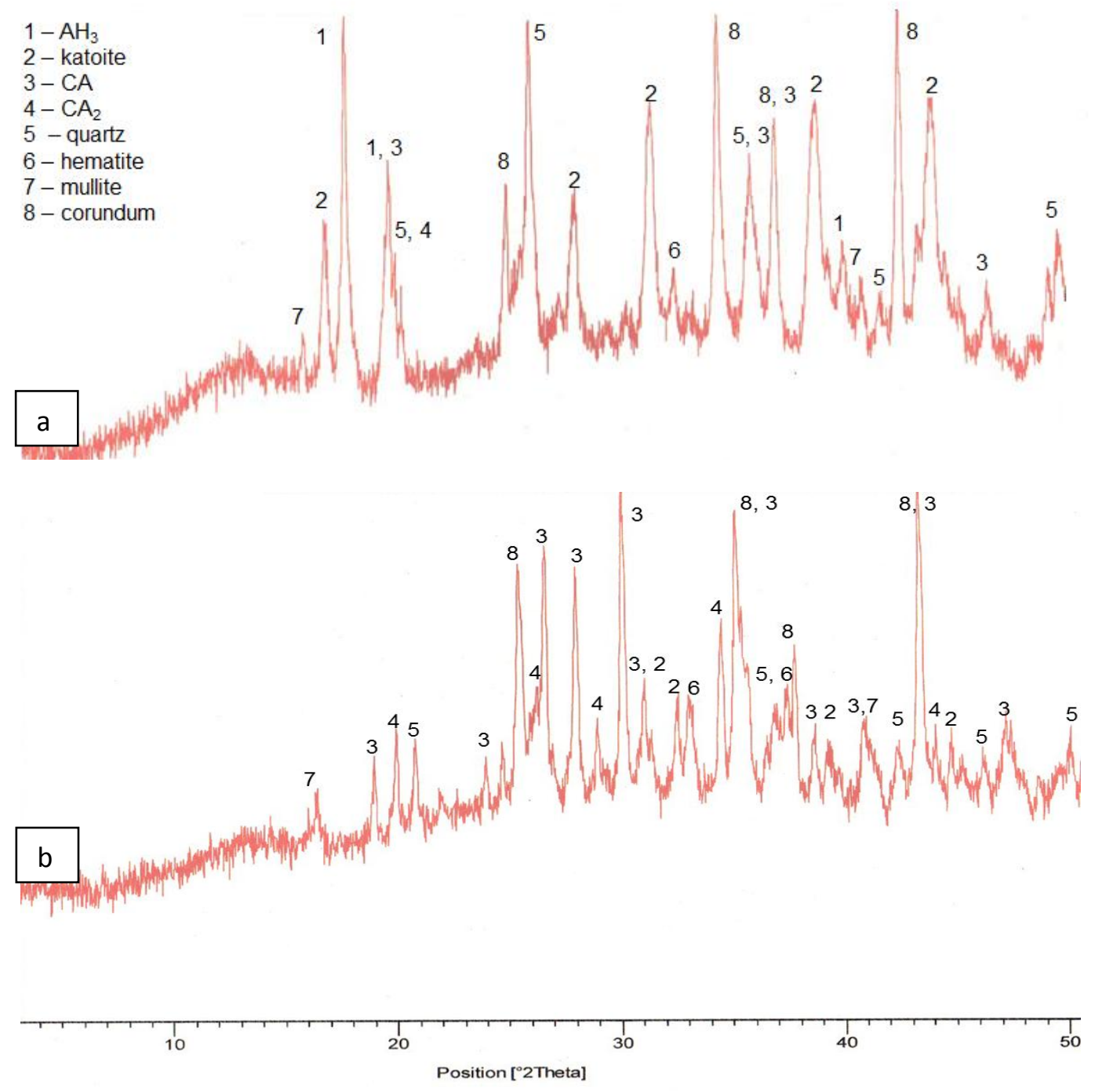

Figure 21. XRD patterns for TSRC hydrated for 2 hours without (a), and with $1 \%$ bwob TA (b).

\subsubsection{Solid phase - $\mu E D X$ study}

The analytical data scatter when phase mixtures are studied with $\mu$ EDX. However, averaging a signal over some mapping areas reveals trends in chemical compositions of the hydrated samples. The measurements were averaged over an area of $2 \times 2 \mathrm{~mm}$. Table 1 summarizes the results for calcium-, aluminum-, and silicon-oxides at two hydration times for samples with and without tartaric acid. There was no major difference in the composition of retarded and nonretarded samples after the first hour of hydration. The concentrations of calcium and aluminum were only slightly higher (at $2 \%$ and $1 \%$ respectively) than for the reference, non-retarded sample, in agreement with lower solution concentration of calcium. However, after the second hour, the concentration of aluminum on the surface of the non-retarded sample increased 
strikingly (77-96\% versus 52\% after the first hour), and, consequently, the concentration of calcium declined while silicon disappeared completely from the sample's surface. For the retarded sample, the concentration of aluminum decreased from 51- to 45-\%, while that of silicon increased (to $29 \%$ from $26 \%$ after the first hour); these findings are in agreement with the decreasing concentration of silicon in solution and point to its precipitation. A rise in the concentration of aluminum on the surface of the non-retarded sample conforms to the XRD- and TGA-data showing the generation of calcium-aluminate hydrate and gibbsite. Both these products precipitate on the surface, covering the originally exposed silicon and calcium. Calcium from calcium-aluminate still is detectable by $\mu \mathrm{EDX}$.

Solutions of non-retarded samples acidified to $\mathrm{pH} 4$ with nitric acid formed a gel. The EDX analysis of the gel revealed that it was mostly composed of aluminum. This confirms that aluminum precipitation from the solutions gave the strong aluminum signal at the surface covered with the gibbsite.

The formation of calcium and sodium alumosilicate hydrates (TGA peak at around $100^{\circ} \mathrm{C}$ ) and of some gibbsite (TGA peak at $250^{\circ} \mathrm{C}$ ) results in the presence of both silicon and aluminum at the surface of the sample containing tartaric acid. In addition, the partial adsorption of tartaric acid, likely as its calcium complex, after two hours of hydration (the TOC measurements show that about $33 \%$ organic carbon is lost from the solution ) leads to relatively constant calcium concentration during the first two hours (18\% and 19\%, respectively after the first- and the second-hour ).

The white precipitate mentioned earlier (Figure 19) that had formed in the centrifuged sample after one hour of cement hydration in the presence of tartaric acid contained, for the most part, aluminum $\left(51 \% \mathrm{Al}_{2} \mathrm{O}_{3}\right)$ and silicon $\left(36 \% \mathrm{SiO}_{2}\right)$, some calcium $(7 \% \mathrm{CaO})$ with minor amounts of iron and potassium. Since no precipitate was formed without tartaric acid, and the FT-IR results revealed carboxylates in the precipitate, we consider that the retarder likely is involved. We hypothesize that mixed calcium-tartrate-aluminate-silicate complexes probably are formed, or that calcium tartrate co-precipitates with the sodium-aluminosilicate hydrates. FT-IR data showing broad, split peaks of mixed monodentate carboxylates confirm these hypotheses. Since $\mu \mathrm{EDX}$ does not measure sodium, its involvement cannot be excluded.

\subsubsection{Effect of tartaric acid on longer-term phase composition - An XRD study}

Measurements of the compressive strength of the retarded samples showed that the retarders had no significant effect at longer hydration times or at higher temperatures $\left(200\right.$ and $\left.300^{\circ} \mathrm{C}\right)$. However, long-term performance of TSRC depends strongly on the hydrates formed after cement set at $85^{\circ} \mathrm{C}$, and after its exposure to higher temperatures of 200 - and $300-{ }^{\circ} \mathrm{C}$. To determine whether the retarder affects the phase composition of cured cement, we analyzed the XRD patterns of TSRC hydrated with $1 \%$ bwob tartaric acid samples and the reference ones after 3 days of hydration at $85^{\circ} \mathrm{C}$ and autoclaving at 200 or $300^{\circ} \mathrm{C}$. 
The major differences between the retarded and control samples at $85^{\circ} \mathrm{C}$ included: stronger signals from hydration products for the control sample, including those for katoite and gibbsite and the presence of some hydrates that are absent on the patterns of the retarded sample, among them crystalline calcium silica aluminate hydrate, Linde A (peaks at 7.14 (12.37), 10 (8.84), 12.4 (7.13), 27.16 (3.28), 29.8 (3.0)) [35] (Figure 22). The retarded sample showed smaller peaks of katoite and gibbsite as crystalline hydration products alone with a broad peak between 2 theta of 12.5 and 15 for amorphous hydrates. Both reference and the retarded samples had split and wide katoite peaks likely due to the partial substitution of $(\mathrm{OH})^{-}$by $\left(\mathrm{SiO}_{4}\right)^{-}$with the formation of $\mathrm{C}_{3} \mathrm{AS}_{\mathrm{n}} \mathrm{H}_{\mathrm{m}}$ that engenders the division of the $\mathrm{C}_{3} \mathrm{AH}_{6}$ lines [35].

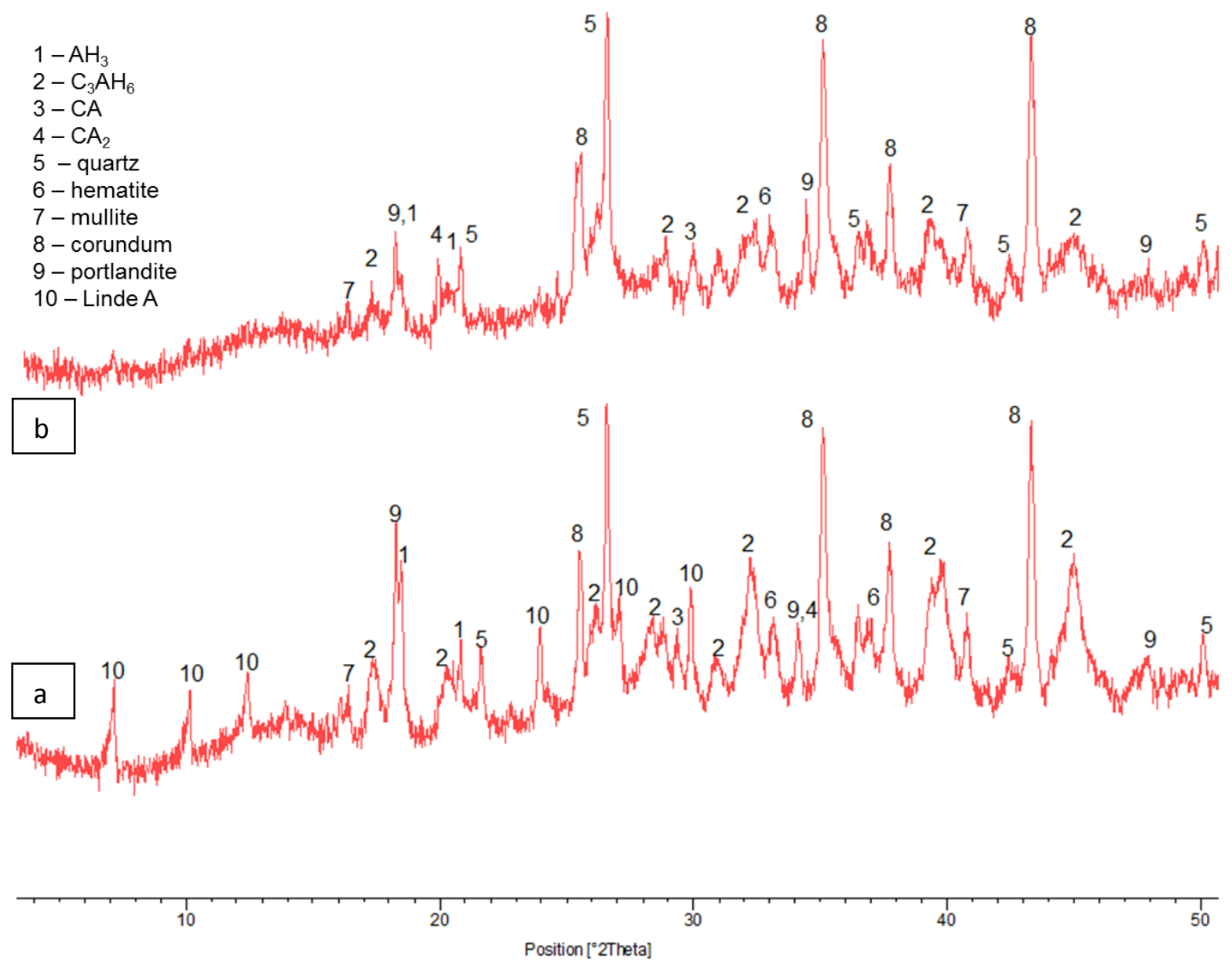

Figure 22. XRD patterns of TSRC hydrated for 72 hours at $85^{\circ} \mathrm{C}$ without (a), and with $1 \%$ bwob TA (b)

The peaks of crystalline products were not as intense and sharp in the retarded sample at both 200- and $300-{ }^{\circ} \mathrm{C}$ as in the reference sample (Figure 23). Both Linde A and gibbsite formed at $85^{\circ} \mathrm{C}$ in the reference TSRC survived through exposure to $200^{\circ} \mathrm{C}$ but significantly declined at 
$300^{\circ} \mathrm{C}$ where boehmite replaced the gibbsite for the most part (Figure 24). The intermediate katoite peaks were strong at $200^{\circ} \mathrm{C}$ and survived well to $300^{\circ} \mathrm{C}$ for this sample.

In contrast, the Linde $\mathrm{A}$ crystals that were absent at $85^{\circ} \mathrm{C}$ in the sample with tartaric acid were only minor at $200^{\circ} \mathrm{C}$, and absent again at $300^{\circ} \mathrm{C}$. Small peaks of intermediate katoite crystals appeared at $200^{\circ} \mathrm{C}$ and were replaced by hydrogarnet at $300^{\circ} \mathrm{C}$. Gibbsite peaks were very weak at $200^{\circ} \mathrm{C}$ and boehmite appeared along with gibbsite in the presence of TA. Noticeably, hydroxysodalite produced stronger peaks at $300^{\circ} \mathrm{C}$ in the retarded sample than in the control. This finding is consistent with the higher amount of sodium aluminosilicate hydrate gel, measured in TGA tests, formed in the presence of tartaric acid. Gel crystallization at higher temperatures would lead to the formation of hydroxysodalite.

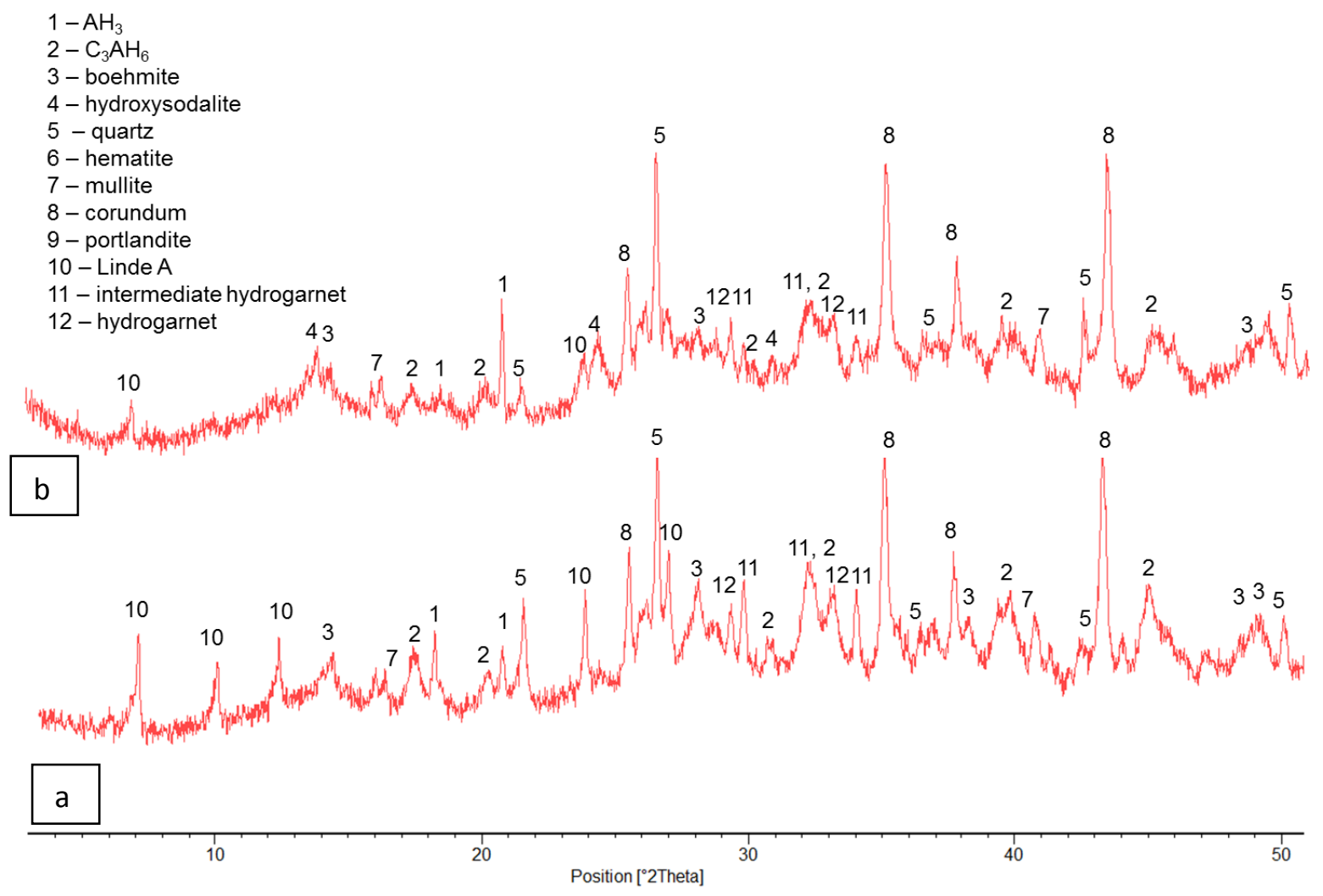

Figure 23. XRD patterns of TSRC hydrated for 72 hours at $85^{\circ} \mathrm{C}$ and 24 hours at $200^{\circ} \mathrm{C}$ without (a), and with $1 \%$ bwob TA (b). 


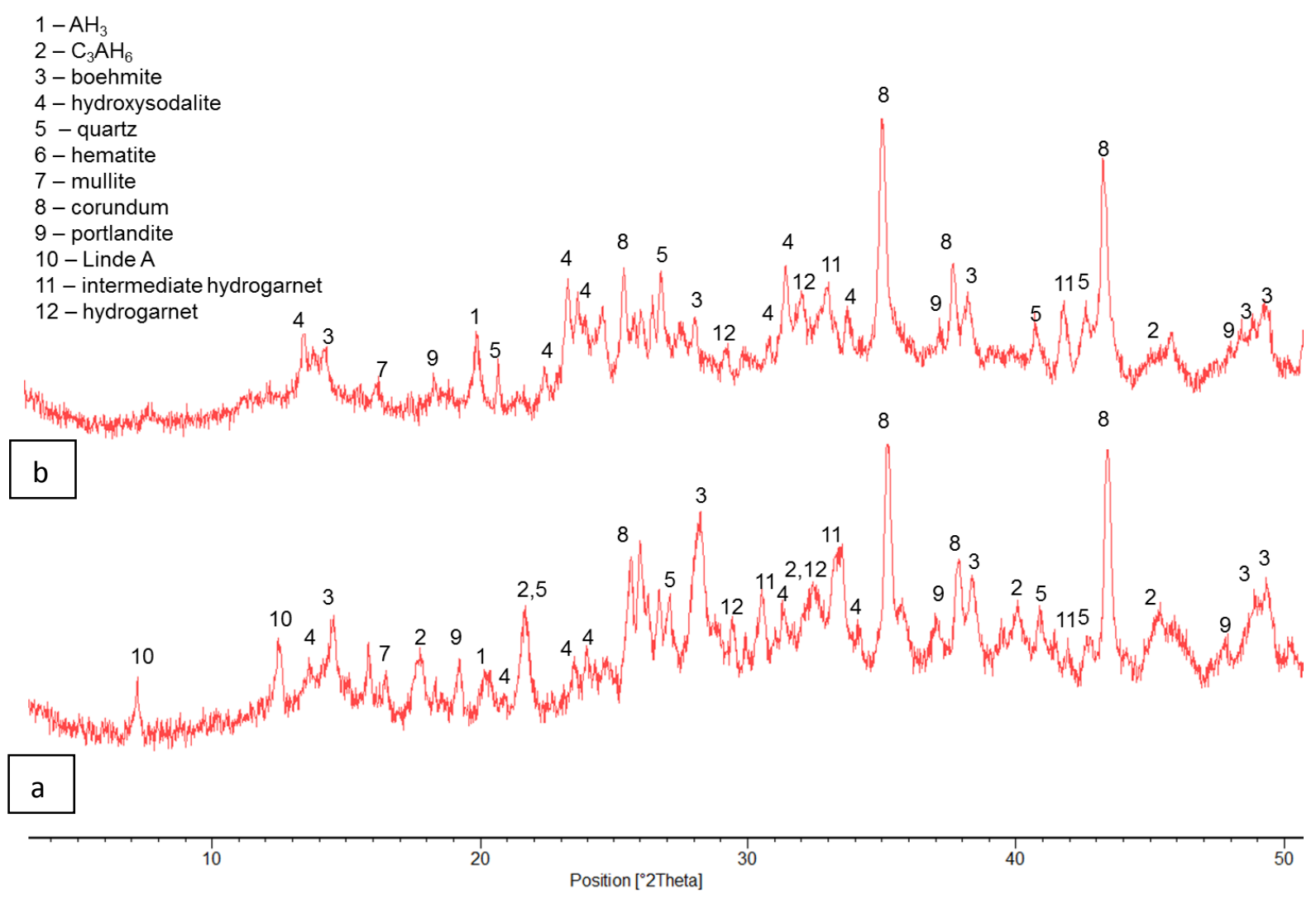

Figure 24. XRD patterns of TSRC hydrated for 72 hours at $85^{\circ} \mathrm{C}$ and 24 hours at $300^{\circ} \mathrm{C}$ without (a), and with $1 \%$ bwob TA (b).

\subsubsection{Discussion}

There is a general agreement between our studies with high- and low-tartaric acid concentrations. Both suggest that tartaric acid interacts with sodium- and calcium-cations and formation of polysilicate ions from sodium metasilicate.

The FT-IR data show mixed cation-complexes of tartaric acid. The high solution concentrations of calcium and organic carbon in retarded samples after short hydration times suggest that calcium is involved in the complexation. Tartaric acid has multiple coordination sites and may complex with several metal ions through its carboxylic groups and hydroxyls [32]. In the present case the complexation through carboxylic groups with both sodium and calcium ions as suggested by FT-IR, at both high- and low- concentrations of tartaric acid. FT-IR measurements also suggest that silicate chains are formed. Since sodium silicate with a high $\mathrm{SiO}_{2} / \mathrm{Na}_{2} \mathrm{O}$ ratio strongly retards CAC hydration [10, 11 and the present study] we can reasonably suggest that sodium complexation by tartaric acid, and polysilicate formation in the solution slowed the hydration of CAC. Other processes that promote the formation of polysilicates include an increase in temperature, the release of silicon ions during the alkali activation of fly ash $\mathrm{F}$, the 
complexation of calcium by tartaric acid with formation of a negatively charged aluminum-rich surface requiring a counterion for balance, so resulting in sodium surface binding and sodium charge balance in aluminum-substituted silicate chains forming upon the dissolution of fly ash $\mathrm{F}$ [37]. The increased concentrations of silicon on the hydrating cement surfaces, as we showed by micro EDX, along with the decreasing concentration of the silicon in solution in retarded samples point to polysilicate-surface interactions.

Tartaric acid also affects aluminum interactions in the slurry. It clearly slowed down the precipitation of gibbsite to the point that boehmite was formed at higher temperatures to the same extent as was gibbsite in the retarded sample, while the control sample showed a massive precipitation of gibbsite already after 2 hours of hydration. The results of FT-IR- and EDXmeasurements indicate that instead of precipitating on solids, aluminum participated in forming some aluminosilicate hydrates in solution, possibly with the involvement of calcium and tartaricacid (the FT-IR and EDX data on the precipitate from the centrifuged TA-modified slurry after the first hydration hour). After 2 hours of hydration, the surface concentrations of calcium and silicon had increased, while aluminum had slightly decreased. These changes were accompanied by a decrease in the dissolved organic carbon that suggests the precipitation of calcium-tartrate with aluminum-silicate. Significant precipitation of calcium tartrate on the cement surface is unlikely since the concentrations of both calcium and organic carbon remain high in the solution through the first hours of hydration. However, poisoning of dissolution sites could suffice to delay the hydration of the cement.

On the other hand, the high concentrations of aluminum revealed by ICP-OES in the solutions of control samples resulted in the precipitation of hydration products containing both aluminum and calcium. The TGA and XRD patterns clearly indicate formation of such amorphous and crystalline hydrates as aluminum-silicate gel (with calcium and sodium as the counter-ions), gibbsite, and katoite in control samples in the first 2 hours of hydration. These data are confirmed by the high concentrations of aluminum in the gel formed in acidified solutions of the reference samples and by the massive precipitation of aluminum on the samples' surfaces as demonstrated by EDX analysis.

Integrating all this information allowed us to propose the following pathway of TSRC hydration in the presence, and in the absence of tartaric acid.

In the control sample sodium metasilicate dissolves forming sodium cations and silicate anions, while CAC goes through a congruent dissolution of calcium aluminates, with the calcium oxygen bonds being the easier to break, so engendering the release of calcium and some aluminum ions into the solution [19]. Fly ash F simultaneously releases aluminum and silicon that nucleate with formation of polymeric chains wherein the tetrahedral of $\mathrm{Si}$ and $\mathrm{Al}$ is randomly distributed and cross-linked with the charge balanced by sodium and calcium (from CAC). When the nuclei reach a critical size, the crystal growth begins. The crystallization process is faster for CAC and, in the presence of a silicate activator, results in formation of 
katoite and calcium-aluminum silicate hydrate $[35,36]$. The crystallization of FAF hydration products is slower, so for a while, only amorphous products exist.

In the presence of tartaric acid, the following major changes in hydration occur. Tartaric acid reacts with sodium from the dissolution of SMS and calcium from that of CAC, so forming calcium- or mixed calcium-sodium-tartrates (see above). The silicon ions released by SMS and FAF form polymeric chains with sodium and calcium, thereby balancing the charge. Calcium bridging of monodentate tartrates and silicon-aluminum chains can occur, so further preventing crystallization of the hydrates. In addition, the polysilicates as well as tartrates retard the dissolution of CAC and the release of aluminum ions through reactions with active dissolution sites, which results in lower dissolved aluminum concentration in the retarded slurry. Significant amount of the retarder stays in the solution preventing nuclei growth and hydrates crystallization. As more and more dissolution sites form, tartrates and the silicates are adsorbed out of the solution (decrease of the concentration of dissolved organic carbon) and hydration proceeds. Many hydrates precipitate as amorphous products that crystalize at later times.

The XRD data unambiguously show delayed crystallization of hydrates in slurries with TA. The delay entails crystallization of the final, high-temperature stable hydrates without going through the intermediates. Importantly, this resulted in a higher intensity of the hydroxysodalite at $300^{\circ} \mathrm{C}$ in retarded samples than in the control where lower-temperature crystalline products consume silicon and hydroxysodalite forms as a result of their re-crystallization.

\section{Conclusions}

In sodium metasilicate (SMS)-activated calcium aluminate cement (CAC)/Class F fly ash slurry system, SMS had two important effects at $85^{\circ} \mathrm{C}$ : One effect was to enhance the extent of hydrolysis of the water-inert fly ash, so promoting its dissolution; the other was to interfere with the hydration of CAC. We hypothesize that SMS, along with fly ash, participated in the formation and precipitation on CAC of ionic sodium polysilicate, so delaying CAC hydration.

Among the various retarders including oxalic acid, D-(-)- tartaric acid, citric acid, and boric acid, tartaric acid (TA) was the most effective in delaying the onset time and the time between the start and the end of the heat release in calorimetric tests at $85^{\circ} \mathrm{C}$. We believe that the carboxylic acid, $\mathrm{COOH}$, group within TA reacted with sodium from SMS and calcium from CAC to form the tartrates of sodium, calcium and sodium/calcium. The consumption of sodium and calcium in the tartrate salts further promoted formation of polysilicate ions that interfered with CAC hydration. The tartrate salts, in turn, reacted with the active dissolution sites of CAC and possibly with Na-Al-Si- chains, through bridging calcium and so preventing dissolution in the first case, and formation of crystalline products in the second one.

Delayed aluminum dissolution and calcium-aluminum-silicate crystallization entailed the changed crystalline-phase composition of retarded samples, where high-temperature stable hydrates form directly without going through the intermediate crystalline phases in retarded samples. Sodium-aluminum-silicate hydrate, Lind A that clearly crystallizes at $85-$ and $200-{ }^{\circ} \mathrm{C}$ in control samples, barely forms in the presence of tartaric acid. The gibbsite appearing as a major 
phase in the XRD patterns of the reference sample at these temperatures and that is replaced by boehmite only at $300^{\circ} \mathrm{C}$ is partially replaced by boehmite already at $200^{\circ} \mathrm{C}$ in the retarded sample. Another important difference in phase composition is evident at $300^{\circ} \mathrm{C}$. The peaks of hydroxysodalite, ceramic-type phase formed from fly ash F hydrates, are more important in the presence of tartaric acid at $300^{\circ} \mathrm{C}$. Its presence is desirable in the hydrated cement since this phase provides good material resistance to temperature variations, enhances bonding properties, and is expected to be chemically resistant.

Importantly, our study revealed the setting time of the blend via calorimetric measurements and visual observations. Such results cannot be related to the actual setting (stiffening) time of cement for evaluation of the pumping time. Our further work will determine whether the selected retarder assures sufficient pumping time in thickening- $\backslash$ time tests under conditions of shear and pressure.

\section{References}

1. S. Gill S, T. Pyatina, and T. Sugama, Thermal shock-resistant cement, Geothermal Resources Council Transaction, 36 (2012) 445-51.

2. E. Nelson and V. Barlet-Gouedard, Thermal cements, In Well Cementing, 2nd ed. (E. Nelson and D. Guillot (ed.)). Schlumberger, Sugar Land, USA.

3. J. Bensted, Current calcium aluminate applications in well plugging, in Calcium aluminate cements, Proceedings of the Centenary Conference (C. Fentiman, R. Mangabhai and K. Scrivener, (ed.)), HIS BrePress (2007) 345-356.

4. J. Young, Effect of organic compounds on the interconversions of calcium aluminate hydrates. Hydration of monocalcium aluminate, Cem. Concr. Res., 1 (1971) 113-122.

5. S. Rodger and D. Double, The chemistry of hydration of high alumina cement in the presence of accelerating and retarding admixtures, Cem. Concr. Res., 14 (1984) 73-82.

6. T. Emoto and T.A. Bier, Rheological behavior as influenced by plasticizers and hydration kinetics, Cem. Concr. Res., 37 (2007) 647-654.

7. J. Bensted, I.C. Callaghan, and A. Lepre, Comparative study of the efficiency of various borate compounds as set-retarders of class $\mathrm{G}$ oilwell cement, Cem. Concr. Res., 21 (1991) 663-668.

8. T. Sugama, N.R. Carciello, and G. Gray, Alkali carbonation of calcium aluminate cements: Influence of set-retarding admixtures under hydrothermal conditions, J. Mater. Sci., 27 (1992) 4900-4916.

9. S. Rai, N.B. Singh, and N.P. Singh, Interaction of tartaric acid during hydration of Portland cement, Indian J. Chem. Tech., 13 (2006) 255-261.

10. I.R. Oliveira, F.S. Ortega, and V.C. Pandolfelli, Hydration of CAC cement in a castable refectory matrix containing processing additives, Ceramics Inter., 35 (2009) 1545-1552.

11. J. Ding, Y. Fu, J. Beaudoin, Study of hydration mechanism in the high alumina cementsodium silicate system, Cem. Concr. Res., 26 (1996) 799-804.

12. V. Antonovich, S. Goberis, A. Shpokauskas, The reaction character between aluminous cement and liquid glass, Chem. Technol. 3 (1999) 55-58.

13. S. Goberis and V. Antonovich, Influence of sodium silicate amount on the setting time and EXO temperature of a complex binder consisting of high-aluminate cement, liquid glass and metallurgical slag, Cem. Concr. Res., 34 (2004) 1939-1941. 
14. F. Winnefeld, A. Leemann, M. Lucuk, P. Svoboda, and M. Neuroth, Assessment of phase formation in alkali activated low and high calcium fly ashes in building materials. Constr. Build. Mater., 24 (2010) 1086-1093.

15. A. Palomo, M.W. Grutzeck and M.T. Blanco, Alkali-activated fly ashes A cement for the future, Cem. Concr. Res., 29 (1999) 1323-1329.

16. C. Shi and R.L. Day, A calorimetric study of early hydration of alkali-slag cements, Cem. Concr. Res., 25 (1995) 1333-1346.

17. D. Ravikumar and N. Neithalath, Reaction kinetics in sodium silicate powder and liquid activated slag binders evaluated using isothermal calorimetry, Thermochim Acta, 546, (2012) 32-43.

18. S. Chithiraputhiran and N. Narayanan, Isothermal reaction kinetics and temperature dependence of alkali activation of slag, fly ash and their blends, Constr. Build. Mater., 45 (2013) 233-242.

19. S.R. Klaus, J. Neubauer, F. Goetz-Neunhoeffer, Hydration kinetics of $\mathrm{CA}_{2}$ and CAinvestigations performed on a synthetic calcium aluminate cement, Cem. Concr. Res. 43 (2013) 62-69.

20. Y.M. Hon, H.Y. Chung, K.Z. Fung, and M.H. Hon, NMR and FT-IR investigation of spinel $\mathrm{LiMn}_{2} \mathrm{O}_{4}$ cathode prepared by the tartaric acid gel process, J. Solid State Chem. 160 (2001) 368-376.

21. U. Regmi, M. Palma, and C.G. Barroso, Direct determination of organic acids in wine and wine-derived products by fourier transform infrared (FT-IR) spectroscopy and chemometric techniques, Analytical Chimica Acta, 732 (2012) 137-144.

22. T. Uchino, T. Sakka, and M. Iwasaki "Interpretation of hydrated states of sodium silicate glasses by infrared and raman analysis," J. Am. Ceram. Soc. 74 (1991) 306-313.

23. J. Fujita, A.E. Martell, and K. Nakamoto, Infrared spectra of metal chelate compounds VI. A normal coordinate treatment of oxalate metal complexes, J. Chem. Phys. 36 (1962) 324-331.

24. I. Quasim, A. Firdous, B. Want, S.K. Khosa, and P.N. Kotru, Single crystal growth and characterization of pure and sodium-modified copper tartrate, J. Crystal Growth, 310 (2008) 5357-5363.

25. M.B. Yue, T. Xue, W.Q. Jiao, Y.M. Wang, and M.Y. He, CTAB-directed synthesis of mesoporous $\gamma$-alumina promoted by hydroxyl carboxylate: The interplay of tartrate and CTAB, Solid Sate Sci. 13 (2011) 408-416.

26. V.C. Farmer and J.D. Russell, The infra-red spectra of layer silicates, Spectrochimica Acta, 20 (1964) 1149-1173.

27. A.A. Kine and M.E. Mullins, and B.C. Cornilsen, Sol-gel kinetics followed by cylindrical attenuated total reflectance infrared spectroscopy, J. Am. Ceram. Soc., 74 (1991) 2559-2563.

28. M.A. Trezza and A.E. Lavat, Analysis of the system $3 \mathrm{CaO} \cdot \mathrm{Al}_{2} \mathrm{O}_{3}-\mathrm{CaSO}_{4} \cdot 2 \mathrm{H}_{2} \mathrm{O}-\mathrm{CaCO}_{3}-$ $\mathrm{H}_{2} \mathrm{O}$ by FT-IR spectroscopy, Cem. Concr. Res. 31 (2001) 869-872.

29. L. Fernandez-Carrasco and E. Vazquez, Reactions of fly ash with calcium aluminate cement and calcium sulphate, Fuel, 88 (2009) 1533-1538.

30. K.V. Saban, T. Jini, and G. Varghese, Influence of magnetic field on the growth and properties of calcium tartrate crystals, J. Magnetism and Magnetic Mater. 265 (2003) 296-304. 
31. J.W. Nicholson, Chemistry of glass-ionomer cements: A review, Biomaterials, 19 (1998) 485-494.

32. E. Bermejo, R. Carballo, A. Castineiras and A.B. Lago, Coordination of $\alpha-$ hydroxycarboxylic acids with first-row transition ions, Coord. Chem. Rev., 257 (2013) 2639-2651.

33. T. Bakharev, Geopolymeric materials prepared using class F fly ash and elevated temperature curing, Cem. Concr. Res. 35 (2005) 1224-1232.

34. C. Gosselin and K.L. Scrivener, Microstructure development of calcium aluminate cements accelerated by lithium sulfate, Proceedings of the Centenary Conference (C. Fentiman, R. Mangabhai and K. Scrivener, (ed.)), HIS BrePress (2007)109-122.

35. A. Fernandez-Jimenez, T. Vazquez and A. Palomo, Effect of sodium silicate on calcium aluminate cement hydration in highly alkaline media: a microstructural characterization, J. Am. Ceram. Soc., 94 (2011) 1297-1303.

36. J.M. Rivas Mercury, X. Turrillas, A.H. de Aza and P. Pena, Calcium aluminates hydration in presence of amorphous $\mathrm{SiO}_{2}$ at temperatures below $90^{\circ} \mathrm{C}$, J. Solid. State Chem., 179 (2006) 2988-2997.

37. A. Fernandez-Jimenez, A. Palomo, M. Criado, Microstructure development of alkaliactivated fly ash cement: a descriptive model, Cem. Concr. Res. 35 (2005) 1204-1209. 